British Journal of Nutrition (2016), 115, 449-465

(C) The Authors 2015. This is an Open Access article, distributed under the terms of the Creative

Commons Attribution licence (http://creativecommons.org/licenses/by/4.0/), which permits unrestricted

re-use, distribution, and reproduction in any medium, provided the original work is properly cited.

\title{
Examining the potential clinical value of curcumin in the prevention and diagnosis of Alzheimer's disease
}

\author{
K. G. Goozee ${ }^{1,2,4}$, T. M. Shah ${ }^{2,3}$, H. R. Sohrabi ${ }^{2,3}$, S. R. Rainey-Smith ${ }^{2,3}$, B. Brown ${ }^{2,3}$, G. Verdile ${ }^{2,3,4,5}$ and \\ R. N. Martins ${ }^{1,2,3,4 *}$ \\ ${ }^{1}$ McCusker KARVIAH Research Centre, Anglican Retirement Villages, Sydney, NSW 2154, Australia \\ ${ }^{2}$ School of Medical Sciences, Centre of Excellence for Alzheimer's Disease Research and Care, Edith Cowan University, \\ Joondalup, WA 6027, Australia \\ ${ }^{3}$ Sir James McCusker Alzheimer's Disease Research Unit, Hollywood Private Hospital, Nedlands, WA 6009, Australia \\ ${ }^{4}$ School of Psychiatry and Clinical Neurosciences, University of Western Australia, Crawley, WA 6009, Australia \\ ${ }^{5}$ School of Biomedical Sciences, Curtin Health Innovation Research Institute Biosciences, Curtin University, Bentley, WA 6102, \\ Australia \\ (Submitted 13 July 2015 - Final revision received 1 October 2015 - Accepted 21 October 2015 - First published online 14 December 2015)
}

\begin{abstract}
Curcumin derived from turmeric is well documented for its anti-carcinogenic, antioxidant and anti-inflammatory properties. Recent studies show that curcumin also possesses neuroprotective and cognitive-enhancing properties that may help delay or prevent neurodegenerative diseases, including Alzheimer's disease (AD). Currently, clinical diagnosis of AD is onerous, and it is primarily based on the exclusion of other causes of dementia. In addition, phase III clinical trials of potential treatments have mostly failed, leaving disease-modifying interventions elusive. $\mathrm{AD}$ can be characterised neuropathologically by the deposition of extracellular $\beta$ amyloid (A $\beta$ ) plaques and intracellular accumulation of tau-containing neurofibrillary tangles. Disruptions in $\mathrm{A} \beta$ metabolism/clearance contribute to $\mathrm{AD}$ pathogenesis. In vitro studies have shown that $\mathrm{A} \beta$ metabolism is altered by curcumin, and animal studies report that curcumin may influence brain function and the development of dementia, because of its antioxidant and anti-inflammatory properties, as well as its ability to influence A $\beta$ metabolism. However, clinical studies of curcumin have revealed limited effects to date, most likely because of curcumin's relatively low solubility and bioavailability, and because of selection of cohorts with diagnosed $\mathrm{AD}$, in whom there is already major neuropathology. However, the fresh approach of targeting early AD pathology (by treating healthy, pre-clinical and mild cognitive impairment-stage cohorts) combined with new curcumin formulations that increase bioavailability is renewing optimism concerning curcumin-based therapy. The aim of this paper is to review the current evidence supporting an association between curcumin and modulation of AD pathology, including in vitro and in vivo studies. We also review the use of curcumin in emerging retinal imaging technology, as a fluorochrome for $\mathrm{AD}$ diagnostics.
\end{abstract}

Key words: Curcumin: Alzheimer's disease: Amyloid: Retinal imaging

With the ageing of many populations worldwide, it is predicted that over the next few decades there will be a marked increase in the number of people with dementia. Current estimations show that 35.6 million people worldwide have dementia, which is predicted to more than triple to 115 million by $2050^{(1)}$. Of all the dementia sub-types, Alzheimer's disease (AD) is the most common. $\mathrm{AD}$ is a neurodegenerative disease, which is characterised clinically by the progressive loss of memory and cognitive functioning. Major pathological features of an $\mathrm{AD}$ brain include the accumulation of extracellular plaques and fibrils, intracellular neurofibrillary tangles (NFT), as well as chronic inflammation and widespread synaptic and neuronal loss, leading to brain atrophy and dysfunction. The deposition of amyloid plaques is suggested as a defining feature of the $\mathrm{AD}$ brain, as NFT are featured in other neurodegenerative diseases $^{(2,3)}$ (although plaques have also been reported in cases of non-AD dementias). Nevertheless, hyper-phosphorylated tau protein, the major component of NFT, may have a critical role in the progression of $\mathrm{AD}$, as it acts together with the major protein component of amyloid plaques, $\beta$ amyloid (A $\beta$ peptides), driving neurodegeneration ${ }^{(4,5)}$. The $\mathrm{A} \beta$ peptide is generated from its parent molecule, amyloid precursor protein (APP), via sequential proteolytic processing by the enzymes $\beta$-APP-cleaving enzyme-1 (BACE1) and $\gamma$-secretase ${ }^{(6)}$, to generate multiple $\mathrm{A} \beta$ forms of varying amino acid lengths. $\mathrm{A} \beta$ peptides aggregate readily into oligomers and fibrils, and

Abbreviations: AD, Alzheimer's disease; A $\beta, \beta$ amyloid; APP, amyloid precursor protein; BACE1, $\beta$-APP-cleaving enzyme-1; BBB, blood-brain barrier; BDNF, brain-derived neurotropic factor; NFT, neurofibrillary tangles; PSD-95, post-synaptic density 95.

* Corresponding author: Professor R. N. Martins, fax +61 89347 4299, email ralph.n.martins@gmail.com 
small oligomers of the longer, more easily aggregating 42 -amino-acid form $(\mathrm{A} \beta 1-42)$ are considered to be the most neurotoxic $\mathrm{A} \beta$ species in the $\mathrm{AD}$ brain. Amyloid deposition is thought to occur early in the disease process ${ }^{(7)}$, and the accumulation of small $\mathrm{A} \beta$ aggregates ('oligomers') is thought to have a critical role in early pathogenic events that include tau hyperphosphorylation and accumulation, oxidative stress and inflammatory processes that lead to neurodegeneration in the $\mathrm{AD}$ brain $^{(4,8,9)}$.

With no current effective disease-modifying treatments available, finding pharmacological/non-pharmacological strategies to halt or slow disease progression is of significant importance. The failure of potential pharmaceuticals in human clinical trials has highlighted the need for research into early diagnosis of $\mathrm{AD}$. This is because of the considerable synaptic loss, neuronal loss and brain shrinkage already present by the time $\mathrm{AD}$ clinical symptoms emerge, with treatments aimed at slowing the progress of the disease more likely to be effective before onset of symptoms, preferably at the earliest pre-clinical stage. The continuing lack of effective pharmaceutical drugs has also prompted the evaluation of alternative therapeutics, such as nutraceuticals. Curcumin is one example where, because of its properties as an anti-inflammatory, antioxidant, $\mathrm{A} \beta$-lowering agent and $\mathrm{A} \beta$ aggregation inhibitor, it shows potential as a therapeutic for $\mathrm{AD}$. In addition, because of its ability to fluoresce and bind $\mathrm{A} \beta$, curcumin has potential as an imaging agent for diagnostics. This review outlines in vitro, in vivo and human studies that have evaluated the therapeutic potential of curcumin in $\mathrm{AD}$, and it discusses recent research that has assessed curcumin as a diagnostic tool through its use in emerging retinal imaging technologies. All human studies identified in this review met current National Institute of Health and the Alzheimer's Association diagnostic guidelines ${ }^{(10)}$.

\section{Beneficial properties of curcumin - historical perspective}

Curcumin is extracted from turmeric, a spice that is derived from the rhizomes of Curcuma Longa and which belongs to the Zingiberaceae (ginger) family. Turmeric is a perennial herb, native to the monsoon forests of south-east Asia, and it is commonly used in Indian, Asian and Middle Eastern foods. In addition to being used as a culinary spice, turmeric (Sanskrit Haridra, meaning that which is yellow) has been a frequently prescribed herbal medicine. Reputed for its blood-purifying abilities $^{(11-13)}$, Ayurveda medicine and traditional Persian and Chinese medicine have prescribed curcumin for centuries for its body-cleansing properties, as well as for pain associated with inflammation of the skin and muscles. Curcumin has also been prescribed for asthma, bronchial hyperreactivity, allergy, anorexia, coryza, cough, sinusitis and hepatic disease ${ }^{(14)}$.

Only $3-5 \%$ of turmeric comprises the yellow-pigmented chemically active curcuminoids, being curcumin (diferuloylmethane), demethoxycurcumin (DMC) and bisdemethoxycurcumin $(\mathrm{BDMC})^{(15)}$. Curcumin, considered the most therapeutic of the three curcuminoids, was first isolated in 1815 by Vogel and Pelletier ${ }^{(16)}$, although its chemical structure was not confirmed until almost a century later ${ }^{(17)}$

The twenty-first century has witnessed renewed interest in curcumin's reputed therapeutic effects, which has resulted in considerable scientific enquiry and review ${ }^{(13,16,18-21)}$. Cell studies $^{(22-24)}$ report curcumin to possess powerful antiinflammatory properties, whereas further research in a variety of inflammatory conditions demonstrates its potential. For example, animal and cell culture studies show that curcumin reduces inflammation in arthritis ${ }^{(25,26)}$; human cell line studies show that curcumin is effective in the management of irritable bowel syndrome ${ }^{(27)}$ and in human clinical trials for psoriasis and other skin disorders ${ }^{(28,29)}$. Anti-proliferative and anti-angiogenic influences of curcumin have also been demonstrated, and its therapeutic benefits are shown in human cancer cell and tissue culture, including prostate ${ }^{(30)}$, breast ${ }^{(31)}$, pancreatic $^{(32)}$ and bowel cancer $^{(33)}$, as well as head and neck squamous cell carcinoma ${ }^{(34)}$.

Curcumin is also considered a powerful antioxidant, reported to be several times more potent than vitamin $\mathrm{E}$ as a free-radical scavenger ${ }^{(35)}$. Curcumin's anti-inflammatory and antioxidant properties have more recently been investigated with respect to $\mathrm{AD}$, as it is now well established that oxidative stress ${ }^{(36)}$ and chronic inflammation are central in the early pathogenic stages of $\mathrm{AD}^{(37)}$. However, in addition to curcumin altering $\mathrm{AD}$ development through anti-inflammatory and antioxidant properties, curcumin's ability to bind to $\mathrm{A} \beta$, influence deposition and aggregation, while possibly also modulating tau processing, has attracted considerable interest in $\mathrm{AD}$ research laboratories ${ }^{(38-41)}$.

Extracellular $\mathrm{A} \beta$ plaques and intraneuronal hyperphosphorylated tau are recognised as hallmark neuropathological features of $\mathrm{AD}^{(42-44)}$ in addition to oxidative stress and inflammation, and it is believed that abnormal $\mathrm{A} \beta$ metabolism, resulting in high levels of toxic $\mathrm{A} \beta$ oligomers, combined with oxidative stress and inflammation form an $\mathrm{AD}$ pathogenic cycle of neurodegeneration. While the initiating step of this neurodegeneration remains to be elucidated, these changes are thought to begin decades before clinical diagnosis; in fact, the accumulation of $\mathrm{A} \beta$ has been shown in radiological imaging to start 20 years or more before the first clinical signs of $\mathrm{AD}^{(45)}$. A $\beta$ accumulation is reported to be associated with impaired synaptic function ${ }^{(46)}$, reduced neurite outgrowth ${ }^{(47)}$, cerebral atrophy ${ }^{(48,49)}$ and reduced cognitive performance, particularly when deposited within the temporal region ${ }^{(50)}$. Synaptic/neuronal loss and NFT load have been shown to correlate positively with cerebral atrophy and cognitive decline, whereas cerebral $\mathrm{A} \beta$ load also correlates with cognitive decline, although to a lesser extent ${ }^{(7)}$. However, there is also a large body of evidence suggesting that small oligomers of $\mathrm{A} \beta$ are particularly toxic to neurons, causing membrane damage, $\mathrm{Ca}^{2+}$ leakage, oxidative damage, disruptions to insulin signalling pathways and synaptic function, as well as mitochondrial damage ${ }^{(51-53)}$. As mentioned above, $\mathrm{A} \beta$-induced changes are believed to occur early in the disease process, and the findings indicate that interventions that can interrupt the production of $\mathrm{A} \beta$ or $\mathrm{A} \beta$ oligomers, or facilitate their removal from the central nervous system, are highly desirable. Modelled projections suggest that delaying the onset of dementia by even 1 year may reduce the worldwide burden of cases in people over 60 years by as much as approximately $10 \%{ }^{(54)}$, whereas the introduction of an intervention that delays the onset of dementia by 5 years could reduce the incidence by almost half ${ }^{(55,56)}$. Therefore, early pre-clinical prevention therapy, which could influence the accumulation or clearance of cerebral $\mathrm{A} \beta$ and tau pathology, and/or 
reduce oxidative stress and chronic inflammation, thus slowing or reversing these pathological changes, would be highly significant for the reduction of $\mathrm{AD}$ prevalence.

Potentially neuroprotective properties of curcumin: animal studies and in vitro anti- $\beta$ amyloid activity of curcumin prevents $\beta$ amyloid aggregation

The $\mathrm{A} \beta$ peptide aggregates readily, first into small aggregates of $\mathrm{A} \beta$ known as $\mathrm{A} \beta$ oligomers and then these oligomers aggregate further to form fibrils, larger fibrils and ultimately plaques of $\mathrm{A} \beta$. Although plaques and large fibrils are the easiest to detect immunohistochemically, these are considered to be relatively inert: as mentioned above, there is now considerable evidence that small $\mathrm{A} \beta$ oligomers are the main neurotoxic species ${ }^{(57)}$. Therefore, it is interesting that substantial data from in vitro studies indicate that curcumin can bind to $\mathrm{A} \beta$ and influence its aggregation. For example, curcumin has been shown to inhibit fibril formation and extension, as well as to destabilise pre-formed fibrils in a dose-dependent manner, effective at concentrations about $0 \cdot 1-1 \cdot 0 \mu \mathrm{M}^{(58)}$. Later studies have similarly shown that curcumin can inhibit the formation of small $\mathrm{A} \beta$ aggregates (A $\beta$ oligomers) in a dose-dependent manner ${ }^{(59,60)}$.

Studies have investigated how curcumin influences $\mathrm{A} \beta$ aggregation, and different theories have emerged - for example, one theory involves curcumin binding to metal ions. Biometals such as $\mathrm{Cu}(\mathrm{Cu}(\mathrm{II}))$ and $\mathrm{Zn}(\mathrm{Zn}$ (II)) are found in abundance in the brain, particularly at synapses. Dysregulation of metal homeostasis can lead to the binding of these particular metal ions to $\mathrm{A} \beta$, and many studies have shown that this binding accelerates $\mathrm{A} \beta$ aggregation. In fact, elevated levels of certain metal ions have been associated with $\mathrm{AD}^{(61)}$, and considerable research has been undertaken to understand the normal roles of these ions in the brain, as well as the roles the ions may have in disease pathogenesis, particularly the roles of $\mathrm{Cu}(\mathrm{II})$ and $\mathrm{Zn}$ (II) on $\mathrm{A} \beta$ aggregation $^{(62)}$. Some recent studies have suggested that curcumin complexes with $\mathrm{Cu}$ (II) and/or $\mathrm{Zn}$ (II) and that this inhibits the transition from less structured oligomer to $\beta$-sheet-rich $\mathrm{A} \beta$ protofibrils, which in turn act as seeding factors for further $\mathrm{A} \beta$ fibrillisation $^{(63)}$. Recent studies looking at the effect of curcumin and curcumin derivatives on metal-induced $\mathrm{A} \beta$ aggregation have shown that Gd-linked curcumin (Gd-Cur, a potential A $\beta$ imaging agent), compared with curcumin and Cur-S, a water-soluble form of curcumin, could modulate $\mathrm{Cu}$-induced $\mathrm{A} \beta$ aggregation to a greater extent ${ }^{(64)}$, supporting the concept of therapeutic and diagnostic uses for the Gd-Cur compounds.

Other theories do not involve metal ions; instead, they suggest that curcumin's ability to bind $\mathrm{A} \beta$ and inhibit its aggregation is because of curcumin's three structural features: a hydroxyl substitution on the aromatic end group, a rigid linker region between 8 and $16 \AA$ in length and a second terminal phenyl group ${ }^{(59)}$. More recent studies using atomic force microscopy have found that curcumin (and another small-molecule inhibitor resveratrol) binds to the $\mathrm{N}$ terminus (residues 5-20) of $\mathrm{A} \beta 1-42$ monomers and prevents oligomers of $1-2 \mathrm{~nm}$ in size from becoming larger $3-5 \mathrm{~nm}$ oligomers ${ }^{(65)}$. Yet another recent study has used NMR spectroscopy to investigate the structural modifications of $\mathrm{A} \beta 1-42$ aggregates induced by curcumin, and found that curcumin induces major structural changes in the Asp-23-Lys-28 salt bridge region and near the A $\beta 1-42$ $\mathrm{C}$ terminus ${ }^{(66)}$. The study also used electron microscopy to show that the A $\beta 1-42$ fibrils are disrupted by curcumin. Interestingly, in a Drosophila AD model, curcumin-fed flies showed accelerated conversion of pre-fibrillar to fibrillar $\mathrm{A} \beta$, thereby reducing the neurotoxicity of pre-fibrillar $\mathrm{A} \beta^{(67)}$. Overall, curcumin effects are not limited to modulation of $\mathrm{A} \beta$ aggregation, and further studies are needed to determine which effect(s) are the most relevant in promoting brain health in pathological cognitive decline.

\section{Curcumin influences $\beta$ amyloid production}

In vitro studies have shown that $\mathrm{A} \beta$ production is influenced by curcumin, as curcumin has been found to inhibit the production of A $\beta$ peptides by altering APP trafficking through the secretory pathway ${ }^{(24)}$. Zhang et al. treated mouse primary cortical neurons with different concentrations of curcumin (1-20 $\mu \mathrm{m})$ for $24 \mathrm{~h}$ and found that both $\mathrm{A} \beta 1-40$ and $\mathrm{A} \beta 1-42$ levels significantly decreased compared with controls. It was suggested that curcumin could stabilise an immature form of APP and reduce the amount reaching the cell surface, thus being available for endocytosis a process necessary for $\mathrm{A} \beta$ production. In an APP-transfected human embryonic kidney cell culture model (SwAPP HEK293), BDMC was shown to reduce BACE1 messenger RNA (mRNA) and protein levels, whereas DMC only affected BACE1 mRNA expression ${ }^{(68)}$. Furthermore, in other studies using a neuronal cell line (pheochromocytoma cells - the PC12 cell line) 3-30 $\mu \mathrm{m}$ curcumin suppressed A $\beta$-induced BACE1 up-regulation ${ }^{(69,70)}$. Most recently, in studies of an $\mathrm{AD}$ Drosophila model, it was found that the curcumin component BDMC was the most effective at rescuing the flies from the morphological and behavioural defects caused by the overexpression of APP and $B A C E 1^{(71)}$, possibly via inhibition of the BACE1 enzyme. Recognising curcumin's ability to reduce $\mathrm{A} \beta$ production, by reducing $B A C E 1 \mathrm{mRNA}$ and its corresponding protein ${ }^{(72)}$, curcumin has been used as a potent positive control in the analysis of other compounds/drugs that target not only BACE1 but also metal chelation, $\mathrm{A} \beta$ aggregation and oxidation ${ }^{(73)}$. In support of curcumin's metal chelation properties, curcumin was shown to prevent the up-regulation of $A P P$ and $B A C E 1$ induced by supraphysiological levels of the metal ions $\mathrm{Cu}(\mathrm{II})$ and $\mathrm{Mn}^{(74)}$.

\section{Curcumin can inhibit $\beta$ amyloid-induced toxicity}

Previous studies support the notion that curcumin can reduce A $\beta$-induced toxicity. A study by Park et $a l .{ }^{(75)}$ used PC12 cell cultures pre-treated with $10 \mu \mathrm{g} / \mathrm{ml}$ curcumin before $\mathrm{A} \beta$ exposure. Compared with controls, pre-treated cells had a significant reduction in oxidative stress, as well as lower Ca influx, resulting in protection against DNA damage and cell death. Curcumin (1-30 $\mu \mathrm{M})$ has also been shown to attenuate the production of A $\beta$-induced radical $\mathrm{O}_{2}$ species in neuronal cell cultures, and $20 \mu \mathrm{M}$ curcumin has been shown to prevent structural changes in $\mathrm{A} \beta$ towards $\beta$-sheet-rich secondary structures ${ }^{(69)}$. Furthermore, the protection curcumin provided to PC12 cells and to human umbilical vein endothelial cells against $\mathrm{A} \beta 1-42$-induced injury was attributed by Kim et al. ${ }^{(76)}$ to antioxidant mechanisms of 
curcuminoids. More recently, in vitro studies of microglia have shown that curcumin can dampen inflammatory pathways that promote neurodegeneration ${ }^{(77)}$. In this study, curcumin dose-dependently improved viability against $\mathrm{A} \beta-42$-induced inflammation, as it abolishes $\mathrm{A} \beta-42$-induced $\mathrm{IL}-1 \beta$, IL- 6 and TNF- $\alpha$ production. Curcumin was also shown to reduce ERK1/2 and p38 phosphorylation, which was then shown to reduce cytokine production by the microglia ${ }^{(77)}$.

Curcumin's neuroprotective properties may also be attributed to its role in cell signalling. Cell signalling by the Wnt pathways, via the transcription co-activator $\beta$-catenin, controls embryonic development, cellular proliferation and neurogenesis. Disruptions to this pathway have been shown to have a significant role in the pathogenesis of diverse diseases such as cancer, metabolic diseases, osteoporosis, epilepsy, as well as AD. In studies of APP-transfected neuroblastoma cells, curcumin was found to activate the $\mathrm{Wnt} / \beta$-catenin signalling pathway by inhibiting the activity of glycogen synthase kinase $3 \beta(\text { GSK- } 3 \beta)^{(78)}$. GSK- $3 \beta$ is a negative regulator of $\mathrm{Wnt}$, and thus lowering its activity will activate Wnt. However, just as importantly, constitutively active GSK-3 $\beta$ contributes to aberrant tau phosphorylation and NFT formation, which are hallmark pathological changes in $\mathrm{AD}^{(79)}$, and thus curcumin-induced inhibition of GSK- $3 \beta$ may also reduce NFT formation. However, the benefits of curcumin in attenuating tau phosphorylation and accumulation have yet to be investigated thoroughly. Interestingly, $\mathrm{A} \beta$ oligomers have also been shown to inactivate Wnt in hippocampal slices, by inducing the Wnt antagonist Dickkopf- ${ }^{(80)}$. These studies collectively suggest that curcumin can influence GSK- $3 \beta$ and Wnt $\beta$-catenin signalling, which are both key factors in $\mathrm{AD}$ pathogenesis ${ }^{(81)}$. Furthermore, it has been shown recently that activation of the $\mathrm{Wnt} / \beta$-catenin signalling pathway inhibits the transcription of BACE1 by binding of T-cell factor- 4 to the BACE1 promoter gene, thereby reducing the generation of $\mathrm{A} \beta^{(82)}$. Other recent studies using molecular modelling software programs have identified curcumin and rosmarinic acid as promising ligands that mimic the inhibitory action of peptidyl inhibitors of caspase $-3^{(83)}$. The relationships between $\mathrm{AD}$-related proteins and pathways discussed above provide further indication of curcumin's therapeutic potential for the prevention of $\mathrm{AD}$.

\section{Curcumin and the clearance of $\beta$ amyloid}

One anti-AD therapeutic approach involves enhancing the clearance of $\mathrm{A} \beta$ from the brain. Several mechanisms have been proposed to assist normal clearance of $\mathrm{A} \beta$ from the brain, such as enhancing receptor- or apo-mediated transport across the blood-brain barrier (BBB), efflux of $\mathrm{A} \beta$ from the brain being the basis of the peripheral sink hypothesis, targeted immune responses to $\mathrm{A} \beta$, dissolution of amyloid fibrils and microglial activation resulting in phagocytosis of amyloid plaques, as reviewed by Bates et al. ${ }^{(84)}$. The significance of the innate immune system in $\mathrm{A} \beta$ clearance remains pertinent to intervention and treatment modalities. Although previous attempts to use vaccines to augment the immune response were halted because of the incidence of sterile encephalitis ${ }^{(85)}$, interest in this area remains strong. Macrophage activity and phagocytosis of $\mathrm{A} \beta$ has been reported to be deficient in $\mathrm{AD}$, suggesting a contributory factor to
$\mathrm{A} \beta$ accumulation ${ }^{(86)}$. Furthermore, a later study that pre-treated the $\mathrm{AD}$ macrophages with curcuminoids resulted in increased $\mathrm{A} \beta$ uptake in $50 \%$ of the macrophages ${ }^{(87)}$.

Curcumin's ability to reduce oxidative damage and amyloid pathology in $\mathrm{AD}$ transgenic mice, demonstrated by Garcia-Alloza et $a l^{(40)}$, also suggests that curcumin can influence amyloidinduced cytopathology, or macrophage processing of amyloid. Garcia-Alloza et al. used multi-photon and in vivo imaging to reveal a marked amyloid clearance effect, with 30\% plaque size reduction and slowed plaque development, in animals receiving curcumin for $7 \mathrm{~d}$ via intravenous tail injections. Fiala et $a l^{\left({ }^{(86)}\right.}$ examined curcumin's effect on enhancing phagocytosis of $\mathrm{A} \beta$ at a molecular level, and found that curcumin restored the normal $\mathrm{A} \beta$-induced up-regulation of the transcription of $\beta-1,4$-mannosyl-glycoprotein $4 \beta-N$-acetylglucosaminyltransferase (MGAT3), an enzyme thought to be involved in phagocytosis. Other proteins such as toll-like receptors were also up-regulated. These results indicate that curcumin may correct immune defects in $\mathrm{AD}$ patients, suggesting a novel approach to $\mathrm{AD}$ immunotherapy ${ }^{(88)}$. In more recent studies by the same group, it was found that $1 \alpha, 25(\mathrm{OH})_{2}$-vitamin $\mathrm{D}_{3}\left(1,25 \mathrm{D}_{3}\right)$ could restore the defective $\mathrm{A} \beta$ phagocytosis in $\mathrm{AD}$ macrophages, and that a nuclear vitamin $\mathrm{D}$ receptor antagonist could block this phagocytosis. All phagocytes seemed to respond to $1,25 \mathrm{D}_{3}$, yet only a subset responded to curcuminoids by up-regulating MGAT3. Nevertheless, in those who did respond, further studies demonstrated that the $1,25 \mathrm{D}_{3}$ bound to a pocket of the vitamin $\mathrm{D}_{3}$ receptor that influences genomic events, and curcuminoids bound to a non-genomic pocket ${ }^{(89,90)}$, produced an additive effect.

\section{Curcumin effects on lipid metabolism}

Early research ${ }^{(91-93)}$ reported that curcumin had cholesterollowering ability, supported by Peschel et al. ${ }^{(94)}$ who reported that curcumin has a hypocholesterolaemic effect, based on its effect on hepatic gene expression. Feng et al. ${ }^{(95)}$ also found curcumin to lower cholesterol levels through suppression of Niemann Pick C1-like 1 protein, which is responsible for the uptake of cholesterol through vesicular endocytosis within the intestine. Another potential mechanism for the hypocholesterolaemic effect of curcumin was revealed in studies of rats fed a high-fat diet, in which curcumin was found to decrease significantly the serum levels of TAG, total cholesterol and LDL-cholesterol, when compared with a control group: curcumin was found to up-regulate mRNA levels of cholesterol $7 \alpha$-hydroxylase (CYP7A1), a rate-limiting enzyme in the biosynthesis of bile acid from cholesterol ${ }^{(96)}$. More recently, treatment of similar high-fat diet-fed rats with curcumin combined with piperine was found to produce similar changes to the serum lipid profiles of the rats and increased HDL levels, resulting in significant up-regulation of the activities and gene expression of apo A-I, lecithin-cholesterol acyltransferase, CYP7A1 and the LDL receptor ${ }^{(97)}$. As hypercholesterolaemia continues to be considered a likely contributor to $\mathrm{AD}$ risk $^{(98,99)}$, the use of curcumin if proven to lower cholesterol could represent another approach, adding to the armoury for $\mathrm{AD}$ risk reduction. 


\section{Curcumin and telomerase}

Xiao et $a l^{(100)}$, investigating the role of telomerase (a ribonuclear protein complex that synthesises and elongates telomeric DNA) in the neuroprotective efficacy of curcumin, found curcumin to be protective against $\mathrm{A} \beta$-induced oxidative stress and cell toxicity. This neuroprotection was lost when telomerase was inhibited by telomerase RT small interfering RNA, indicating that the neuroprotection provided by curcumin was dependent on the presence of telomerase.

\section{Focusing on findings in animal studies}

Several in vivo studies have found that $\mathrm{A} \beta$ deposition and plaque burden in AD-model transgenic mice is decreased following treatment with curcumin ${ }^{(40,60,101,102)}$. Curcumin has also been found to inhibit $\mathrm{A} \beta$-induced tau phosphorylation ${ }^{(103)}$, to reduce microglial activation, indicating a reduction in inflammation $^{(102,104)}$, and reduced oxidative damage ${ }^{(104)}$. Other studies of transgenic mouse models of $\mathrm{AD}$ have shown that curcumin can reduce genomic instability events ${ }^{(105)}$.

In the study by Lim et al. ${ }^{(101)}$, AD-model Tg2576 mice aged 10 months old were fed a curcumin diet (160 parts per million (ppm)) for 6 months. The results showed that the curcumin diet significantly lowered the levels of oxidised proteins, the inflammatory cytokine, IL- $1 \beta$, the astrocyte marker glial fibrillary acidic protein (GFAP), soluble and insoluble $\mathrm{A} \beta$ and also plaque burden. The study found that the reduction in GFAP was localised, such that increased activity was shown in areas around plaques, demonstrating a stimulatory effect of curcumin on the phagocytosis of plaques by microglia. Frautschy et $a l^{(104)}$, using Sprague-Dawley rats infused with $\mathrm{A} \beta 40$ and $\mathrm{A} \beta 42$ to induce neurodegeneration and $\mathrm{A} \beta$ deposits, found that dietary curcumin $(2000 \mathrm{ppm}(5.43 \mu \mathrm{mol} / \mathrm{g}))$ suppressed $\mathrm{A} \beta$-induced oxidative damage and memory impairment, and increased microglial labelling within areas adjacent to $\mathrm{A} \beta$ deposits. They also found that curcumin reversed changes in synaptophysin and post-synaptic density 95 (PSD-95) levels, associated with brain plasticity, as well as improved rat performance in length and latency within the water maze test ${ }^{(104)}$. In similar studies of aged Tg2576 AD-model mice by Yang et $a l^{(60)}$, it was demonstrated that curcumin injected peripherally (via the carotid artery) can cross the BBB and bind to amyloid plaques and inhibit the formation of $\mathrm{A} \beta$ oligomers and fibrils ${ }^{(60)}$. Later, Begum et al. $^{(15)}$ showed similar results and suggested that the dienone bridge present in the chemical structure of curcumin is necessary for this reduction in plaque deposition and the lower protein oxidation observed in the curcumin-treated $\operatorname{Tg} 2576$ mice.

More recently, Belviranli et al. ${ }^{(106)}$ showed that aged female rats supplemented with curcumin for $12 \mathrm{~d}$ demonstrated improved spatial memory (Morris water maze test), and their brains exhibited reduced oxidative damage. In other studies using an $\mathrm{A} \beta$-infused male Sprague-Dawley rat model of $\mathrm{AD}$, the effects of combined curcuminoids, as well as the individual curcumin constituents, were examined in relation to genes related to synaptic plasticity. The genes that were investigated included actin, $\mathrm{Ca} /$ calmodulin-dependent protein kinase type IV, PSD-95 and synaptophysin, and significant effects were noted; for example, a significant increase in synaptophysin expression was found following treatment of the hippocampus with curcuminoids, and both DMC and curcumin were found to increase PSD-95 expression several-fold ${ }^{(107)}$, demonstrating results similar to the earlier rat study carried out by Frautschy et $a{ }^{(104)}$.

\section{Curcumin and neurogenesis}

Curcumin has also been found to stimulate proliferation of embryonic neural progenitor cells and neurogenesis in the adult hippocampus, demonstrating other potentially beneficial effects on neuroplasticity ${ }^{(108)}$. In this study, intraperitoneally administered curcumin activated extracellular signal-regulated kinases (ERK) and p38 kinases, which function in cellular signal transduction pathways that are known to be involved in the regulation of neuronal plasticity and stress responses. More recently, a hybrid compound of curcumin and melatonin (5-(4-hydroxy-phenyl)-3-oxo-pentanoic acid (2-(5-methoxy-1H-indol-3-yl)-ethyl)-amide), known as Z-CMI-1, developed with the aim of improving neuroprotective properties and $\mathrm{BBB}$ permeability, was found to reduce $\mathrm{A} \beta$ accumulation in the hippocampus and cortex of APP/PS1 transgenic mice, and to increase the expression of the synaptic markers synaptophysin and PSD-95, following oral administration at a dose of $50 \mathrm{mg} / \mathrm{kg}$ for 3 months ${ }^{(109)}$, encouraging further development of this hybrid compound. APP/PS1 mice were also used in another recent study, which tested the effect of 6 months' dietary supplementation with the curcumin derivative 1,7-bis(4'-hydroxy3'-trifluoromethoxyphenyl)-4-methoxycarbonylethyl-1,6-heptadiene3,5-dione (FMeC1). It was found that FMeC1 supplementation resulted in less $\mathrm{A} \beta$ deposits, glial cell activity and cognitive deficits, when compared with untreated, curcumin-treated or FMeC2-treated mice, suggesting that FMeC1 has potential in the treatment of $\mathrm{AD}^{(110)}$. In rat studies, genetic transcriptional responses along with enhanced hippocampal neurogenesis was seen, following 12 weeks of administration of a curcumincontaining diet, as compared with 6 weeks of this diet, or a control diet ${ }^{(111)}$, providing further evidence that curcumin may be beneficial through the promotion of neuronal cell growth.

\section{Curcumin and the blood-brain barrier}

Studies of rat and mouse models of ischaemic damage found that curcumin could protect the BBB, most likely because of anti-inflammatory and antioxidant effects ${ }^{(112,113)}$, and later studies of cerebral ischaemia in rats found that a single intravenous injection of curcumin could reduce infarct volume and neurological deficit, possibly because of inhibition of inducible nitric oxide synthase ${ }^{(114)}$. More recent studies suggest that curcumin up-regulates heme oxygenase- 1 expression to reduce damage and permeability of the $\mathrm{BBB}^{(115)}$. Encouragingly, an in vivo rat study, using nanoparticulation of curcumin, was able to demonstrate increased organ, as well as the brain, perfusion by curcumin, by prolonging retention time in the hippocampus by $83 \%$ and in the cerebral cortex by $96 \%{ }^{(116)}$. More recently, another group produced a highly stable nanocurcumin 
formulation (particule size $<80 \mathrm{~nm}$ ) for use within an in vitro and in an $\mathrm{AD}$ transgenic mouse model. The study showed higher concentrations of the nanoformulation in plasma and within the brain compared with non-capuslated curcumin or placebo, while demonstrating significant improvements in working and cued memory function ${ }^{(117)}$

Curcumin analogues with similar biological activity to curcumin, yet with improved pharmacokinetic characteristics, including increased bioavailability and water solubility, are continuing to be developed ${ }^{(118,119)}$, while new synthetic products are also emerging ${ }^{(119)}$. Nanotechnology is particularly promising, whereby nanoencapsulation may be able to achieve a synergistic drug delivery system ${ }^{(120)}$. Encouraging results have already been reported in a study examining curcumin for use in breast cancer chemoprevention, which used injectable polymeric micro particles in mice, achieving both sustained blood curcumin levels for almost a month while maximising its BBB penetration, as well as inhibiting tumour vasculature ${ }^{(121)}$. Other studies exploring nanoparticle technology ${ }^{(122,123)}$ have been equally promising. For example, following the intravenous administration of liposomal curcumin, polymeric nanocurcumin and poly-lactic-co-glycolic acid co-polymer-curcumin in rats, all of these compounds were found to cross the $\mathrm{BBB}^{(122)}$, whereas in another study nanoparticles containing curcumin were shown to increase oral bioavailability 9 -fold ${ }^{(123)}$. Further evidence of BBB penetration has been obtained in animal models using labelled curcumin derivatives $^{(119)}$

\section{Curcumin and acetylcholinesterase}

In addition to the effects above, curcumin has also been shown to influence acetylcholinesterase activities ${ }^{(124)}$, following the same pathway as the commonly prescribed pharmaceuticals, acetylcholinesterase inhibitors, which are considered firstline management in $\mathrm{AD}^{(18,125)}$. The administration of acetylcholinesterase inhibitors has been found in certain circumstances to slow the progression of $\mathrm{AD}$ symptoms or even reduce $\mathrm{AD}$ symptoms for a 12-month period, by inhibiting the breakdown of acetylcholine, a major neurotransmitter, depleted in the $\mathrm{AD}$ brain. Using in vitro and ex vivo models of acetylcholinesterase activity, Ahmed et al. ${ }^{(107)}$ investigated whether curcumin had an influence on acetylcholinesterase mechanisms, and recorded dose-dependent inhibitory effects in the frontal cortex and in the hippocampal tissue; curcuminoids also demonstrated significant attenuation of scopolamine-induced amnesia. Furthermore, Ahmed et al. ${ }^{(107)}$ examined the influence of curcumin on spatial memory in amyloid-infused $\mathrm{AD}$ rat models, reporting increased PSD-95 and synaptophysin expression in the hippocampus and a memory-enhancing effect. In studies of streptozotocin-induced diabetic rats, curcumin has been shown to prevent cholinergic-mediated cortical dysfunctions, which are induced by diabetes ${ }^{(126)}$, and in mice treated with okadaic acid to induce memory impairment orally administered curcumin has been found to improve cholinergic function and reduce inflammation, among other beneficial effects ${ }^{(127)}$. Furthermore, curcumin has been shown to reverse alcohol-induced cognitive deficits in the adult rat brain, partly by preventing the alcoholinduced activation of acetylcholinesterase; curcumin also reduces signs of neuroinflammation in these rats ${ }^{(128)}$. Another rat study indicated that curcumin may inhibit acetylcholinesterase activity in As- and Al-induced toxicity models ${ }^{(129)}$

Despite all these animal studies, the influence of curcumin on acetylcholinesterase has not yet been investigated in human clinical studies. Furthermore, mechanisms underlying many of the effects described above are still being characterised. However, there is now evidence of curcumin derivatives influencing proteasomal function and $\mathrm{A} \beta$ degradation, as described below.

\section{Curcumin, proteasome function and $\beta$ amyloid degradation}

Proteasomal activity and its role in the degradation of most oxidised proteins is linked with the processes of cell ageing; it is also believed that age-related decreases in proteasome activity weakens a cell's capacity to remove oxidatively modified proteins and therefore encourages the development of diseases $^{(130)}$. Curcumin has been demonstrated to have a stimulatory effect on proteasomal activity, causing a $46 \%$ increase in activity at doses of $1 \mu \mathrm{M}$ in vitro, whereas higher doses, not likely to be achieved in vivo, led to decreased $\operatorname{activity}^{(131)}$. More recent studies have shown that a synthetic derivative of curcumin, CNB-001, can stimulate $\mathrm{A} \beta$ degradation through both proteasomes and lysosomes, and the experimental inhibition of the proteasome pathway redirects clearance through lysosomes. Other recent CNB-001 studies have provided a link between the findings of several other AD-related biochemical changes. These include the findings that levels of the enzyme 5-lipoxygenase (5-LOX) are elevated in $\mathrm{AD}^{(132)}$ and that disruption of this enzyme and some phospholipases can reduce AD pathology ${ }^{(133,134)}$; as well as that chronic stress can cause cell signalling/over-activation of regulatory kinases, which in turn leads to the phosphorylation of the eukaryotic initiation factor- $2 \alpha$ (eIF2 $\alpha$ ) and disrupts the translation activation of several mRNA, and detected in neurodegenerative diseases including $\mathrm{AD}^{(135)}$. The $\mathrm{CNB}-001$ studies found that CNB-001 could inhibit 5-LOX, which induces the eIF $2 \alpha$ phosphorylation. Furthermore, when fed to AD transgenic mice, CNB-001 was found to increase eIF $2 \alpha$ phosphorylation (as well as heat shock protein 90 and activating transcription factor 4 levels), improve $\mathrm{A} \beta$ clearance and therefore limit the accumulation of soluble $\mathrm{A} \beta$ and ubiquitinated aggregated proteins. CNB-001 has also been found to maintain the expression of synapse-associated proteins and to improve memory in the mice ${ }^{(136)}$. These studies indicate that the curcuminoid derivative's inhibition of 5-LOX has potential as a therapeutic approach.

Overall, cell culture and animal studies have indicated that curcumin has considerable potential as an inhibitor of $\mathrm{A} \beta$ aggregation, as an antioxidant, an anti-inflammatory and as an inhibitor of BACE1. Curcumin, among its modalities of action, has also shown promise in facilitating $\mathrm{A} \beta$ clearance/ degradation, inhibiting tau phosphorylation, promoting neurogenesis and modulating synaptic plasticity (Fig. 1). Despite these benefits, there is a paucity of populationbased studies examining the protective role of curcumin on cognition. 


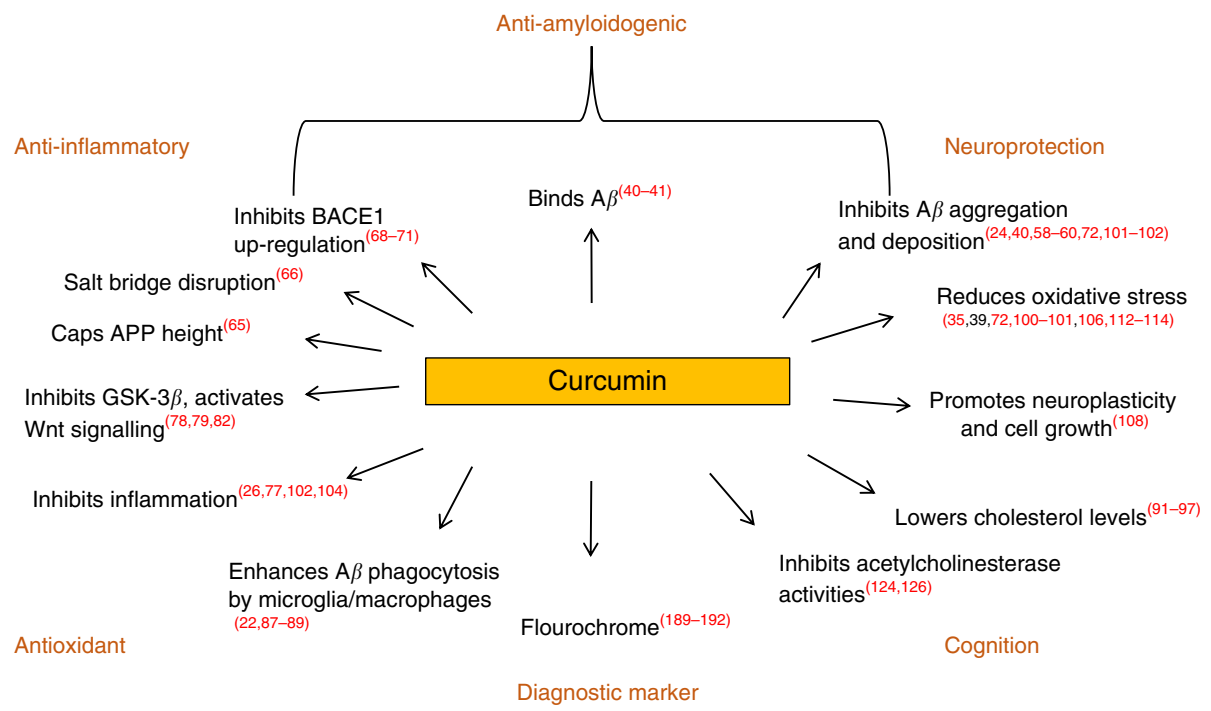

Fig. 1. Curcumin: reported mechanisms of action. BACE1, $\beta$-APP-cleaving enzyme-1; $A \beta, \beta$ amyloid; APP, amyloid precursor protein.

\section{Effects of curcumin on human cognition}

Only a handful of clinical studies have been carried out to evaluate the cognitive enhancing potential of curcumin in $\mathrm{AD}$ patients ${ }^{(137,138)}$; however, these have not been particularly successful. Reasons could be because of the low bioavailability of curcumin $^{(15)}$, thereby markedly reducing its potential to reach the brain at sufficient concentrations to provide benefits. Alternatively, the subjects may have been treated at a stage of pathology that is too advanced for curcumin to provide benefits. Nevertheless, there are epidemiological data that support the concept that curcumin can reduce the risk of $\mathrm{AD}$. For example, India, with an estimated average daily consumption of curcumin being $80-200 \mathrm{mg}^{(21,139)}$, has been reported to have a lower incidence and prevalence of $\mathrm{AD}^{(140-142)}$, although under-reporting and clinician access may be a contributor. Nevertheless, a study of 1010 cognitively intact Asian participants aged 60-93 years has found that those who consumed curry (which contains turmeric) more often, compared with those who ate curry very rarely or never, performed better on the Mini Mental State Examination (MMSE) ${ }^{(143)}$. These observations, among others, support the concept that turmeric, and in particular its curcumin particle, may possess valuable neuroprotective or cognitive-enhancing properties. However, as mentioned above, clinical trials examining the efficacy of curcumin in patients with cognitive decline have been disappointing; however, more recently, with studies using improved formulations and more appropriate cohorts, encouraging signs are emerging ${ }^{(144)}$. Table 1 represents a list of ongoing/completed clinical trials that have used curcumin for the diagnosis, prevention or treatment of $\mathrm{AD}$. These trials are discussed further below.

Baum et al. ${ }^{(137)}$ randomised $\mathrm{AD}$ patients ( $n$ 34) to receive $1 \mathrm{~g}$ (plus $3 \mathrm{~g}$ placebo), $4 \mathrm{~g}$ (plus $3 \mathrm{~g}$ placebo) or $0 \mathrm{~g}$ of oral curcumin (plus $4 \mathrm{~g}$ of placebo), once daily. Participants were given the choice of formulation, being either powder or capsule. The intervention group did not demonstrate significant differences in MMSE scores or plasma $\mathrm{A} \beta-40$ levels between 0 and 6 months; however, it was suggested that the outcome measures were not sensitive or specific enough to demonstrate effects ${ }^{(137)}$. Ringman et al. ${ }^{(145)}$ conducted a 24-week, randomised, double-blind, placebo-controlled study evaluating the efficacy of two dosages of curcumin ( 2 and $4 \mathrm{~g} / \mathrm{d}$ ) in patients with mild-to-moderate $\mathrm{AD}$, with an open-label extension for 48 weeks. This was the first study to include measurement of cerebrospinal fluid (CSF) biomarkers. The preliminary results showed no significant differences in cognitive function, in plasma or CSF $\mathrm{A} \beta-40 / \mathrm{A} \beta-42$ or tau, between placebo and intervention groups; however, bioavailability was again reported as a limitation, although the dosing was well tolerated.

The above studies included AD-diagnosed participants, in whom significant neurodegeneration and $\mathrm{AD}$ pathology already exists. Given that the pathological changes begin two decades or more before the first recognisable symptoms ${ }^{(45)}$, targeting healthy older cohorts or those in the pre-clinical or prodromal $\mathrm{AD}$ phase would more likely provide benefits through slowing the pathogenic mechanisms. Considerable synaptic and neuronal loss has already occurred by the time symptoms appear, and the antioxidant, anti-inflammatory and $\mathrm{A} \beta$-lowering and anti-A $\beta$ aggregation properties of curcumin are most likely to be of benefit in the early stages, for the prevention of $\mathrm{AD}$ pathogenesis. However, curcumin treatment of $\mathrm{AD}$ patients may still provide many benefits, and it warrants further clinical evaluation.

More recent studies have evaluated curcumin's effects under normal physiological conditions. In a placebo-controlled study targeting healthy middle-aged subjects ( $n$ 38, 40-60 years), $80 \mathrm{mg}$ of curcumin ( $400 \mathrm{mg}$ of Longvida-optimised curcumin) was given orally for 4 weeks to assess the health-promoting effects of curcumin ${ }^{(146)}$. This study, because of the diverse health claims of curcumin, investigated several blood and saliva biomarkers, to examine the effect of curcumin on markers associated with lipids, inflammation, liver function, immunity and stress, as well as $\mathrm{A} \beta$ levels. Cognitive measures were not included in their study design. Statistically significant results were shown for a number of these markers including increased catalase, nitric oxide and antioxidant status, with lowered 
Table 1. Studies using curcumin in Alzheimer's disease (AD): diagnosis, prevention and treatment

\begin{tabular}{|c|c|c|c|c|c|}
\hline Study & Agent & Cohort & Dose & Duration & End points and brief summary of results \\
\hline Baum et al. ${ }^{(137)}$ (NCT00164749) & $\begin{array}{l}\text { Curcumin and } \\
\text { ginkgo }\end{array}$ & Probable AD; 50 years $+; n 30$ & $1,4 \mathrm{~g}$ daily & 6 months & $\begin{array}{l}\text { Safety and effects, biochemical and cognitive } \\
\text { measures } \\
\text { No differences detected between treatment groups in } \\
\text { A } \beta \text { levels or MMSE scores }\end{array}$ \\
\hline Ringman et al. ${ }^{(145)}$ (АСT00099710) & $\begin{array}{c}\text { Curcumin } \mathrm{C}_{3} \\
\text { complex }^{\circledR}\end{array}$ & $\begin{array}{l}\text { Mild/moderate } A D ; \text { age } 49 \text { years }+ \text {; } \\
\quad \text { n } 30\end{array}$ & $2,4 \mathrm{~g}$ daily & $\begin{array}{l}24 \text { weeks plus } \\
24 \text { open label }\end{array}$ & $\begin{array}{l}\text { Side effects, blood biomarkers and cognition } \\
\text { No differences detected between treatment groups in } \\
\text { clinical or biomarker efficacy measures; results also } \\
\text { indicated low bioavailability }\end{array}$ \\
\hline Hishikawa et al. ${ }^{(150)}$ & Turmeric capsules & Severe AD; $n 3$ & $\begin{array}{l}100 \mathrm{mg} \text { curcumin } \\
\text { daily }\end{array}$ & $\begin{array}{l}12 \text { months, tested after } \\
12 \text { weeks }\end{array}$ & $\begin{array}{l}\text { MMSE and NPIQ; score on NPIQ decreased } \\
\text { significantly, MMSE increased in } 1 / 3\end{array}$ \\
\hline Poncha (NCT01001637) & Longvida ${ }^{\mathrm{TM}}$ & $\begin{array}{l}\text { Moderate - severe AD; } 50-80 \text { years; } \\
\quad n 160\end{array}$ & $2,3 \mathrm{~g}$ twice daily & 2 months & Efficacy and safety; blood and cognition \\
\hline $\begin{array}{l}\text { Martins \& Goozee } \\
\quad \text { (ACTRN12613000681752) }\end{array}$ & $\begin{array}{l}\text { Biocurcumax } \\
\text { BCM-95 }\end{array}$ & $\begin{array}{l}\text { Retirement living, healthy } 65-90 \text { years; } \\
\quad \text { } 100\end{array}$ & $\begin{array}{l}500 \mathrm{mg} \text {, thrice } \\
\text { daily }\end{array}$ & 12 months & $\begin{array}{l}\text { Cognition, blood biomarkers/chemistry; lifestyle } \\
\text { questionnaires; brain imaging (MRI, PET FDG and } \\
\text { amyloid), retinal imaging }\end{array}$ \\
\hline Martins (ACTRN12611000437965) & $\begin{array}{l}\text { Biocurcumax } \\
\text { BCM-95 }\end{array}$ & $\begin{array}{l}\text { Community living, healthy } 55-75 \text { years; } \\
\quad n 100\end{array}$ & $\begin{array}{l}500 \mathrm{mg} \text {, thrice } \\
\text { daily }\end{array}$ & 12 months & $\begin{array}{l}\text { Cognition, blood biomarkers/chemistry; lifestyle brain } \\
\text { imaging }\end{array}$ \\
\hline Small (NCT01383161) & $\begin{array}{l}\text { Theracurmin } \\
\text { CR-031P'M }\end{array}$ & $\mathrm{MCl} /$ normal ageing $n 132$ & $\begin{array}{l}90 \mathrm{mg} / \mathrm{d} \text { twice } \\
\text { daily }\end{array}$ & 18 months & Cognition; blood; genetic profile \\
\hline Frautschy (NCT018811381) & Longvida and yoga & $\begin{array}{l}\text { Subjective cognitive complainers } 55-90 \\
\text { years; } n 80\end{array}$ & $\begin{array}{l}400 \mathrm{mg} \text {, twice } \\
\text { daily }\end{array}$ & 6 months & Biochemistry, cognition and FDG PET \\
\hline $\begin{array}{l}\text { Cox et al. }{ }^{(144)} \\
\quad \text { (ACTRN12612001027808) }\end{array}$ & Longvida ${ }^{\mathrm{TM}}$ & $\begin{array}{l}\text { Healthy and cognitive decline } 65-80 \\
\text { years; } n 60\end{array}$ & $\begin{array}{l}400,800 \mathrm{mg} \\
\text { daily }\end{array}$ & $\begin{array}{l}\text { Phase 1: acute } 1-3 \mathrm{~h} / \\
4 \text { weeks } \\
\text { Phase 2: } 8 \text { weeks }\end{array}$ & $\begin{array}{l}\text { Cognition, mood and anxiety; blood biomarkers fMRI; } \\
\text { cognition }\end{array}$ \\
\hline $\begin{array}{l}\text { Patterson (NCT00595582 early } \\
\text { termination) }\end{array}$ & $\begin{array}{l}\text { Curcumin } \\
\text { bioperine }\end{array}$ & MCI 55-85 years; $n 10$ & $\begin{array}{l}900 \mathrm{mg} \text { twice } \\
\text { daily }\end{array}$ & 24 months & $\begin{array}{l}\text { Cognition and size of metabolic lesions on the PET } \\
\text { scan }\end{array}$ \\
\hline $\begin{array}{l}\text { Martins \& Goozee } \\
\quad \text { (ACTRN12614001024639) }\end{array}$ & $\begin{array}{l}\text { Biocurcumax } \\
\text { BCM-95 }\end{array}$ & Healthy and $\mathrm{MCl} 65-90$ years; $n 48$ & $\begin{array}{l}500 \mathrm{mg} \text { twice } \\
\text { daily }\end{array}$ & 3 months & Gene regulation and expression; and cognition \\
\hline $\begin{array}{l}\text { Verdooner \& Martins } \\
\quad \text { (ACTRN12613000367741) }\end{array}$ & Longvida ${ }^{\mathrm{TM}}$ & $\begin{array}{l}\text { Healthy, MCI, mild/moderate AD } 50 \\
\text { years+; } n 200\end{array}$ & $\begin{array}{l}20 \text { g daily } \\
\text { (shake) }\end{array}$ & $7 d$ & $\begin{array}{l}\text { Diagnostics; curcumin fluorescence retinal imaging of } \\
\text { A } \beta \text { plaques }\end{array}$ \\
\hline
\end{tabular}

$A \beta, \beta$ amyloid; MMSE, Mini Mental State Examination; PET, positron emission tomography; FDG, fluorodeoxyglucose; MCI, mild cognitive impairment; NPIQ, Neuro-Psychiatric Inventory-Brief Questionnaire; fMRI, functional MRI. 
plasma alanine aminotransferase and TAG, but not total cholesterol. In addition, curcumin was found to lower plasma $\mathrm{A} \beta$ levels. Another interesting finding was that salivary amylase was also significantly lowered, which is an enzyme associated with adrenergic activity during stress ${ }^{(147)}$.

A number of studies of curcumin supplementation in healthy older subjects are still in progress. However, one such study has been completed: a randomised, double-blind placebocontrolled study ( $n$ 60, 60-85 years) using the same $80 \mathrm{mg} / \mathrm{d}$ curcumin formulation as used by DiSilvestro et al. ${ }^{(146)}$ (400 mg of Longvida-optimised curcumin). The authors reported acute ( $1 \mathrm{~h}$ post dose) and chronic (1-month duration) effects of curcumin intake on cognition, mood and blood biomarkers ${ }^{(144)}$. Benefits on attention and working memory were reported following the acute administration of curcumin, whereas at the 1-month time point, working memory and mood improved. Alertness and contentedness also improved after acute-on-chronic treatment.

Although the results above are encouraging, alternate mechanisms, including modulation of the stress response, may have played a part. Amylase, shown to be lowered in an earlier study using curcumin ${ }^{(146)}$, is a recognised biomarker of $\beta$-adrenergic stimulation ${ }^{(147-149)}$, and improved attention, working memory and contentedness may be linked to this mode of action. No alterations in blood levels of $\mathrm{A} \beta-40$ or $\mathrm{A} \beta-42$ levels were detected, although these are not thought to be reliable biomarkers on their own. Differences in cognitive performance, as demonstrated in serial $7-\mathrm{s}$ and delayed recall, were not significant ${ }^{(144)}$. Nevertheless, curcumin did enhance the lipid profile by lowering LDL, and in contrast to the results found by DiSilvestro et $a l^{(146)}$, Cox et $a l^{(144)}$ also recorded a reduction in plasma total cholesterol. Long-term lipid changes such as these may have some effect on $\mathrm{AD}$ risk: as mentioned earlier, chronic conditions linked to abnormal lipid profiles such as obesity and diabetes are linked with a higher risk of $\mathrm{AD}$. Interestingly, a case study reported by Hishikawa et $a l .{ }^{(150)}$ found that three severe-stage $\mathrm{AD}$ patients treated with $100 \mathrm{mg} / \mathrm{d}$ oral curcumin for 12 weeks (in addition to their already prescribed acetylcholinesterase inhibitor, donepezil) showed a reduction in agitation, anxiety and irritability; one patient also showed improvement in MMSE score. This may suggest a role for curcumin as a concurrent intervention, and it supports the concept that curcumin may provide benefits, even in advanced stages of $\mathrm{AD}$; however, further research would be required to support these suggestions.

As mentioned earlier, several other clinical studies are still underway, or results have not yet been published; thus, with so few clinical studies having been completed, it is not possible to make any conclusions concerning the clinical significance of curcumin in enhancing cognition.

\section{Epigenetics, Alzheimer's disease and curcumin}

Epigenetic alterations have been reported to occur in $\mathrm{AD}^{(151-154)}$. As epigenetic alterations are dynamic, these alterations have been proposed as a target area for $\mathrm{AD}$ prevention. Epigenetic alterations include changes in DNA methylation, histone modifications or changes in miRNA expression. Studies including some clinical studies of other conditions have shown that curcumin has the potential to induce epigenetic changes ${ }^{(155,156)}$. For example, epigenetic effects of curcumin have been shown in patients with breast cancer and advanced pancreatic cancer, and also in people at risk of stroke, by providing vascular protection ${ }^{(157)}$. Curcumin has been shown to inhibit DNA methyltransferase, histone acetyltransferase and histone deacetylase, and to modulate miRNA, for example down-regulating microRNA-134 and microRNA-124 in cultured hippocampal slices, which are associated with an increase in the brain-derived neurotropic factor (BDNF) ${ }^{(158)}$. BDNF has been shown to increase hippocampal neuronal survival and to enhance synaptic plasticity. Furthermore, variants of the BDNF gene have been linked to several mental disorders such as major depressive disorder (MDD) and schizophrenia, and low levels of BDNF protein are thought to contribute to the pathology of MDD. Interestingly, antidepressants have also been found to increase blood levels of $\mathrm{BDNF}^{(159)}$. Depression is a major risk factor for $\mathrm{AD}$, and thus this BDNF-modifying property of curcumin is of significant interest. Other recent studies have also found that curcumin can have a significant effect on depression ${ }^{(160)}$, supported to some extent by the studies described above by Cox et $a l^{(144)}$

Many other studies have discovered the beneficial epigenetic effects of curcumin in relation to various cancers and rheumatoid arthritis, and now similar benefits are being discovered that may have an impact on the risk and severity of $\mathrm{AD}^{(161)}$. For example, DNA methylation in neurodegenerative diseases (and many other conditions such as CVD and stroke) has been linked to high homocysteine levels, which occur with ageing and with vitamin $B_{12}$ or folate deficiencies ${ }^{(162,163)}$. Chronically high homocysteine levels lead to an abnormally high DNA methylation ${ }^{(164)}$, which requires DNA methyltransferase, and as mentioned above curcumin inhibits DNA methyltransferase. However, rat studies of homocysteine effects suggest that curcumin may be neuroprotective, and may improve learning and memory deficits, by reducing lipid peroxidation and high malondialdehyde levels, both of which are induced by high homocysteine levels ${ }^{(165)}$. The relative significance of these potential benefits of curcumin dietary supplementation are clearly still not known, and thus further clinical studies are required to evaluate the neuroprotective role of curcumin induced by epigenetic regulation for the prevention of cognitive decline.

\section{Curcumin safety profile, tolerability, bioavailability and mode of administration}

As curcumin is a component of the spice turmeric, it is not surprising that curcumin has been reported to be a very safe nutraceutical with a low side-effect profile. However, it should be noted that while curcumin has been reported to be safe and well tolerated at doses of upto $8 \mathrm{~g} / \mathrm{d}^{(166)}$, studies have not gone beyond 3 months, and thus the long-term effects of high doses of curcumin are not known. In addition, with enhanced bioavailability and absorption now possible with new formulations, the risk of increased toxicity is higher, particularly for populations taking medications metabolised by the liver or for those with existing liver impairment ${ }^{(137)}$. Nevertheless, although curcumin may not have been tested widely for the purposes of reducing 
neurodegeneration, it has been clinically tested in patients with various conditions and pro-inflammatory diseases including cancer, CVD, arthritis, Crohn's disease, ulcerative colitis, irritable bowel disease, tropical pancreatitis, peptic ulcer, psoriasis, atherosclerosis, diabetes, diabetic nephropathy and renal conditions, among others, and has resulted in minimal side effects and many health benefits. Curcumin has also provided protection against hepatic conditions, chronic arsenic exposure and alcohol intoxication $^{(167)}$.

Curcumin's pleiotropic effects explain its wide variety of applications; for example, it has been tested for the purpose of stent coating, as curcumin has advantageous anti-coagulant properties $^{(168)}$. In addition, it can inhibit the generation of blood clotting factors $\mathrm{Xa}$ and thrombin via the extrinsic and intrinsic pathways ${ }^{(169)}$. These properties do indicate that one should be cautious when prescribing curcumin in combination with other blood-thinning preparations. Although the safety of curcumin has been demonstrated ${ }^{(137,145)}$, in humans, oral ingestion of existing formulations has presented challenges concerning absorption and bioavailability ${ }^{(145,170)}$. The literature reports that oral curcumin has efficient first-pass metabolism and some degree of intestinal metabolism, including glucuronidation and sulphation (although this occurs mostly in the liver); however, it is excreted largely unconjugated via the intestine. Curcumin is also unstable at neutral and alkaline $\mathrm{pH}$. There appears to be minimal distribution of curcumin to the liver or other tissues beyond the gastrointestinal tract ${ }^{(171)}$. For example, in rat studies, an oral dose of $500 \mathrm{mg} / \mathrm{kg}$ resulted in a peak plasma concentration of only $1.8 \mathrm{ng} / \mathrm{ml}^{(172)}$, with the major metabolites being curcumin sulphate and curcumin glucuronide, whereas a clinical study found that oral doses of 4,6 and $8 \mathrm{~g}$ of curcumin daily for 3 months yielded serum curcumin concentrations of only 0.51 (SD 0.11), 0.63 (SD 0.06) and 1.77 (SD 1.87) $\mu \mathrm{M}$, respectively, with peak levels at $1-2 \mathrm{~h}$ post dosing ${ }^{(166)}$. Unmodified curcumin is reported to be retained in the blood for $2-5 \mathrm{~h}$ in humans, whereas retention of a modified form of curcumin - Biocurcumax-95 (BCM-95) - is reported as exceeding $8 \mathrm{~h}^{(173)}$. In order for the curcumin to elicit a greater nutraceutical benefit, it is critical that more of it is able to enter the bloodstream, it must have a longer half-life and also cross the BBB to be of significant benefit in $\mathrm{AD}$.

To date, most human curcumin studies have used oral formulations. Absorption and bioavailability have continued to be a hindrance, not aided by the variation of formulations available. However, as technology has advanced and new delivery approaches have emerged, the use of adjuvant therapies, isomerisation, liposomes, micelles, phospholipids and nanotechnology also increase. One of the potential therapeutic results of increasing blood levels of curcumin in humans can hopefully be anticipated from $\mathrm{AD}$ transgenic mouse studies, in which the intravenous administration of curcumin $(7.7 \mathrm{mg} / \mathrm{kg}$ per d) for $7 \mathrm{~d}$ resulted in significant clearance of cerebral $\mathrm{A} \beta \operatorname{load}^{(40)}$. Alternate routes of delivering curcumin are already being used for other disorders, such as the use of topical eye drops, recommended for the treatment of a variety of ophthalmic disorders $^{(174)}$, and transdermal application using encapsulated curcumin as a nanoemulsion, for the treatment of arthritis ${ }^{(175)}$. Recently, the curcumin derivative FMeC1, originally produced as an MRI probe, has been produced in aerosol form for inhalation.
A study in 5XFAD transgenic mice suggested improved distribution in the brain, and immunohistochemical studies demonstrated that FMeC1 absorbed following aerosol delivery did bind to amyloid plaques in the mouse brains ${ }^{(176)}$. This technique may also be useful for $\mathrm{A} \beta$ imaging studies; however, further studies are needed to validate this notion. The absorption and bioavailability of curcumin is highly relevant, and the formulation, dose and mode of delivery are each important factors. Multiple over-the-counter brands are available, and most of them claim increased bioavailability compared with unformulated curcumin; however, independent comparative analysis is essential. Two formulations BCM- $95^{(177,178)}$ and Longvida ${ }^{(145)}$ currently have the strongest independent data available in human trials. For a review of the molecular structure of curcumin and its derivatives, FMeC1 and $\mathrm{FMeC} 2$, see Yanagisawa et $a l^{(110)}$, and differences between the properties of CNB-001 can be examined as previously published $^{(179-181)}$.

To summarise, curcumin has been trialled at doses as high as $8 \mathrm{~g} / \mathrm{d}$, and found to be well tolerated and safe. However, as new formulations are emerging that are showing promise of increasing bioavailability, BBB permeability and longer halflives, these formulations also need to be evaluated in future safety and tolerability trials. Furthermore, as any curcumin therapy is likely to be long-term in nature, much longer treatment times need to be trialled. The animal and clinical studies that have investigated the role of curcumin have applied a variety of administration modes, including oral, subcutaneous, intraperitoneal, intravenous, topical and the nasal route ${ }^{(182)}$. Human trials investigating curcumin's neuroprotective mechanisms have mostly used the oral route; however, future studies should explore other routes of administration.

\section{Curcumin as a fluorochrome/radioligand in Alzheimer's disease diagnosis}

Turmeric has been used as a colouring agent since ancient times. In 1989, Stockert et al. $^{(183)}$ identified curcumin as a potential fluorochrome, as curcumin was found to fluoresce yellow/green under a violet/blue $(436 \mathrm{~nm})$ light, and it was noted to bind to DNA and chromosomes, as treatment of tissue samples and cell samples with deoxyribonuclease or TCA prevented the chromatin staining. More recently, these innate fluorescent qualities (curcumin absorbs light at about $420 \mathrm{~nm}$ and emits fluorescence at about $530 \mathrm{~nm}$ in aqueous solutions $\left.{ }^{(184)}\right)$, and curcumin's natural affinity to bind with $\mathrm{A} \beta$, prompted curcumin to be tested as a safe plaquelabelling fluorochrome. A mouse study investigated novel derivatives of curcumin and measured their binding affinities for $\mathrm{A} \beta$ aggregates $^{(185)}$. The derivative with the highest affinity was then $\left({ }^{18} \mathrm{~F}\right)$-radiolabelled for testing as a radioligand probe for $\mathrm{A} \beta$ plaque imaging; the compound also had suitable lipophilicity, good brain uptake and was metabolically stable in the brain. In another study conducted on transgenic $\mathrm{AD}$ mice, multiphoton microscopy was used to demonstrate that curcumin crossed the BBB and labelled $\mathrm{A} \beta$ plaques and cerebrovascular amyloid angiopathy ${ }^{(40)}$. Curcumin has since been used in the labelling of neuronal fibrillar tau inclusions in human brain samples of $\mathrm{AD}$ and progressive supranuclear palsy ${ }^{(186)}$. More recently, other studies of $\mathrm{A} \beta$ imaging 
used an ${ }^{19} \mathrm{~F}$-containing curcumin derivative injected peripherally in $\mathrm{AD}$-model mice to detect $\mathrm{A} \beta$ plaques in the brains, using $\mathrm{MRI}^{(110)}$. Furthermore, Koronyo-Hamaoui et al. ${ }^{(187)}$ demonstrated curcumin's value as a staining agent for $\mathrm{A} \beta$ by detecting plaques in human postmortem retinal tissue, and also as a brain and retinal $\mathrm{A} \beta$ plaque tracer administered intravenously in transgenic mice. Importantly, the pathology in the retina was detected before the stage at which pathology in the brain could be detected, indicating that curcumin may have potential as a pre-clinical AD biomarker. The research also supports the previous observation that curcumin has the ability to cross the BBB, which is essential for its therapeutic efficacy. Preliminary data from a pilot study ( $n$ 40) conducted by our group undertaking retinal imaging using curcumin as a fluorochrome had a $100 \%$ sensitivity and $80.6 \%$ specificity for $\mathrm{AD}$ diagnosis $^{(3)}$. Another study recruited mild cognitive impairment (MCI) patients ( $n$ 30) and administered $80 \mathrm{mg}$ of curcumin (Meriva) twice daily for $3 \mathrm{~d}$ and found abnormal deposits in different retinal layers believed to be related to neurodegeneration ${ }^{(188)}$. The study reported that curcumin caused patchy hypofluorescent spots; however, it did not quantify the retinal amyloid plaques. The findings were primarily based on the direct perception of the deposits via ocular imaging. Recent studies have again used MRI, this time to detect magnetic nanoparticles made of superparamagnetic iron oxide conjugated with curcumin, which were found to bind to $\mathrm{A} \beta$ aggregates in ex vivo $\mathrm{AD}$-model mouse brains, after injection with the curcumin conjugate ${ }^{(189)}$. Other recent studies have produced a novel nanoimaging agent: $\operatorname{poly}(\beta$-L-malic acid) containing covalently attached $(1,4,7,10-$ tetraazacyclododecane-1,4,7,10-tetraacetic acid) gadolinium and curcumin. The all-in-one agent selectively binds to $\mathrm{A} \beta$ plaques and can be detected by $\mathrm{MRI}^{(190)}$, thus providing another promising $\mathrm{A} \beta$ plaque imaging agent.

Curcumin, being non-toxic, accessible and economical, thus becomes highly attractive for both diagnostics and therapeutic research. As discussed above, retinal imaging using curcumin fluorescence is currently being examined in our research centre as part of the Australian Imaging, Biomarkers and Lifestyle flagship study of ageing, and it has been found to be well tolerated by participants. This approach, combined with examination of the retinal vascular features ${ }^{(191)}$, may deliver a novel diagnostic tool that provides a more reliable indication of early $\mathrm{AD}$ changes, which is economical, relatively non-invasive and widely applicable.

\section{Limitations of curcumin and future directions}

If all the positive results observed in in vitro and in vivo animal studies could be translated into human studies, the significance of curcumin in $\mathrm{AD}$ prevention and treatment would be considerable. The recent study by Cox et al. ${ }^{(144)}$ provided some encouraging outcomes by investigating cognitive markers, but only acute changes in attention, working memory and mood were significant. No effects were reported in long-term memory or executive function; however, the short duration of the study may have been a limitation. The evidence that curcumin can influence $\mathrm{A} \beta$ aggregation and $\mathrm{A} \beta$ clearance, support innate immune systems, reduce oxidative stress, enhance cognition and impede the onset of $\mathrm{AD}$ in humans remains elusive. However, not to be overlooked is the application of curcumin as a diagnostic fluorochrome, potentially assisting in the earlier identification of pre-clinical stages of $\mathrm{AD}$, during retinal scanning. The use of curcumin as a fluorochrome within retinal amyloid imaging, combined with examination of retinal vascular features, offers a novel diagnostic approach to AD. While retinal imaging is acknowledged as a non-invasive, economical and easily translated technology, further validation is required before it can be adopted as an early $\mathrm{AD}$ marker.

Enhanced oral formulations of curcumin are emerging, potentially negating the prior challenges of absorption and bioavailability. However, considering the differences in product formulation, and the multitude of curcumin products already available, comparative analysis would be useful. As the primary focus of $\mathrm{AD}$ treatment has turned to primary prevention, the point of intervention is also crucial: interventions introduced early ( $>10$ years before the onset of AD clinical symptoms) may present difficulty establishing statistically significant changes, whereas interventions introduced 1-2 years before the onset may be less effective or ineffective as the disease pathology may already be too advanced. Prevention studies designed with longer duration are highly desirable; however, as nutraceuticals generally do not attract commercial opportunity, realising these type of studies will be difficult to accomplish.

The use of curcumin as an adjunct therapy to cholinesterase inhibitors, particularly in the early stages of $\mathrm{AD}$, offers a potentially new area of research. As anxiety and stress are common co-morbidities in $\mathrm{AD}$, and research has shown curcumin to have effect in these areas, curcumin may offer an appealing alternative to antidepressant and antipsychotic therapies, while potentially offering other synergies, including influencing the underlying neuropathology and enhancing cholinergic activity. In recent years, the focus on curcumin as a compound of interest for the prevention of $\mathrm{AD}$ has been intensifying. The results of ongoing clinical trials will hopefully shed more light on the benefits of curcumin in the prevention of $\mathrm{AD}$. In line with curcumin's complex modes of action, outcome measures should be expanded to include not just cognitive changes; extensive blood biomarker assays should also be carried out, as well as imaging (e.g. measuring cerebral amyloid load and potentially retinal markers) to characterise curcumin's effects more fully over time, in a pre-clinical population.

\section{Conclusion}

To date, $\mathrm{AD}$ clinical trials have not been able to generate the anticipated benefits of curcumin; however, this has been broadly attributed to difficulties with absorption, bioavailability and arguably the timing and length of intervention. As reviewed in this article, there is significant evidence that curcumin can act on multiple pathways identified in the pathogenesis of $\mathrm{AD}$. It is possible, however, that sporadic $\mathrm{AD}$ in humans with the associated cerebral atrophy and neuronal death may be less responsive to curcumin than the $\mathrm{AD}$ induced in transgenic animal models of the disease.

As discussed in this review, increasing the bioavailability, BBB penetration and sustaining the half-life of curcumin remains a major focus in relation to its dose-response. To achieve the same degree of efficacy in human studies as compared with animal 
studies, closer scrutiny of the administration route and also formulation are required, as increasing bioavailability and BBB penetration is critical. Research analysing the different oral formulations is lacking, and this is an area for further investigation. Furthermore, as the pre-clinical signs of $\mathrm{AD}$ are present decades before its clinical onset and most of the late-stage $\mathrm{AD}$ clinical trials have recently failed, intervention must be focused at preventing or delaying $\mathrm{AD}$ onset. It is reasonable to include healthy community-dwelling older adults and those with subjective memory complaints, in intervention studies with curcumin, for a longer duration with longitudinal follow-up. Last, inclusion of AD-related biomarkers and neuroimaging would add to the clinical significance of curcumin's efficacy in the prevention of $\mathrm{AD}$ and associated cognitive decline.

\section{Acknowledgements}

The authors gratefully acknowledge the combined support of the McCusker Alzheimer's Research Foundation and the Anglican Retirement Villages (ARV).

K. G. G. is supported by a grant through the Foundation for Aged Care, ARV, and a scholarship from the Co-operative Research Centre for Mental Health. R. N. M., T. M. S., H. R. S., S. R. R.-S., B. B. and G. V are supported by the Edith Cowan University and the McCusker Alzheimer's Research Foundation. H. R. S. has received renumeration from Pfizer and Takeda. R. N. M. is the founder and chief scientific officer of the biotech company, Alzhyme. G. V. is supported by the Curtin University Senior Research Fellowship (CRF140196) and the NHMRC (APP1045507).

All authors contributed to the literature search, analysis of the data published, manuscript writing and revisions of the article.

The authors declare no conflicts of interest arising from the conclusions of this research.

\section{References}

1. Prince M \& Jackson J (editors) (2009) Alzheimer's Disease International: World Alzheimer Report. Executive Summary. London: Alzheimer's Disease International.

2. Lee VM, Goedert M \& Trojanowski JQ (2001) Neurodegenerative tauopathies. Annu Rev Neurosci 24, 1121-1159.

3. Frost S, Kanagasingam Y, Macaulay L, et al. (2014) Retinal amyloid fluorescence imaging predicts cerebral amyloid burden and Alzheimer's disease (oral presentation). Alzheimers Dement 10, 234-235.

4. Ittner LM \& Götz J (2011) Amyloid- $\beta$ and tau - a toxic pas de deux in Alzheimer's disease. Nat Rev Neurosci 12, 67-72.

5. Ittner LM, Ke YD, Delerue F, et al. (2010) Dendritic function of tau mediates amyloid-beta toxicity in Alzheimer's disease mouse models. Cell 142, 387-397.

6. Krishnaswamy K, Verdile G, Groth DM, et al. (2009) The structure and function of Alzheimer's gamma secretase enzyme complex. Crit Rev Clin Lab Sci 46, 282-301.

7. Villemagne VL, Burnham S, Bourgeat P, et al. (2013) Amyloid beta deposition, neurodegeneration, and cognitive decline in sporadic Alzheimer's disease: a prospective cohort study. Lancet Neurol 12, 357-367.

8. Walsh DM \& Teplow DB (2012) Alzheimer's disease and the amyloid beta-protein. Progr Mol Biol Transl Sci 107, 101-124.
9. O'Malley T, Oktaviani N, Zhang D, et al. (2014) A beta dimers differ from monomers in structural propensity, aggregation paths and population of synaptotoxic assemblies. Biochem J 461, 413-426.

10. McKhann GM, Knopman DS, Chertkow H, et al. (2011) The diagnosis of dementia due to Alzheimer's disease: recommendations from the National Institute on Aging-Alzheimer's Association workgroups on diagnostic guidelines for Alzheimer's disease. Alzheimers Dement 7, 263-269.

11. Majeed M, Badmaev V \& Murrary F (1996) Turmeric and the Healing Curcuminoids. New Canaan, CT: Keats Publishing Inc.

12. Kelloff GJ, Crowell JA, Steele VE, et al. (2000) Progress in cancer chemoprevention: development of diet-derived chemopreventive agents. $J$ Nutr 130, 467S-471S.

13. Goel A, Kunnumakkara AB \& Aggarwal BB (2008) Curcumin as 'Curecumin': from kitchen to clinic. Biochem Pharmacol 75, 787-809.

14. Ammon HP \& Wahl MA (1991) Pharmacology of Curcuma longa. Plata Med 57, 107.

15. Begum AN, Jones MR, Lim GP, et al. (2008) Curcumin structure-function, bioavailability, and efficacy in models of neuroinflammation and Alzheimer's disease. I Pharmacol Exp Ther 326, 196-208.

16. Zhou H, Beevers CS \& Huang S (2011) Targets of curcumin. Curr Drug Targets 12, 332-347.

17. Milobedeska J, Kostanecki V \& Lampe V (1910) Structure of curcumin. Berichte der Deutschen Chemischen Gesellschaft 43, 2163-2170.

18. Hamaguchi T, Ono K \& Yamada M (2010) Review: curcumin and Alzheimer's disease. CNS Neurosci Ther 16, 285-297.

19. Agarwal DK \& Mishra PK (2010) Curcumin and its analogues: potential anticancer agents. Med Res Rev 30, 818-860.

20. Mishra S \& Palanivelu K (2008) The effect of curcumin (turmeric) on Alzheimer's disease: an overview. Ann Indian Acad Neurol 11, 13-19.

21. Basnet P \& Skalko-Basnet N (2011) Curcumin: an antiinflammatory molecule from a curry spice on the path to cancer treatment. Molecules 16, 4567-4598.

22. Pan MH, Lin-Shiau SY \& Lin JK (2000) Comparative studies on the suppression of nitric oxide synthase by curcumin and its hydrogenated metabolites through down-regulation of IkappaB kinase and NFkappaB activation in macrophages. Biochem Pharmacol 60, 1665-1676.

23. Xu YX, Pindolia KR, Janakiraman N, et al. (1997) Curcumin inhibits IL1 alpha and TNF-alpha induction of AP-1 and NF$\mathrm{kB}$ DNA-binding activity in bone marrow stromal cells. Hematopathol Mol Hematol 11, 49-62.

24. Zhang C, Browne A, Child D, et al. (2010) Curcumin decreases amyloid-beta peptide levels by attenuating the maturation of amyloid-beta precursor protein. J Biol Chem 285, 28472-28480.

25. Joe B, Rao UJSP \& Lokesh BR (1997) Presence of an acidic glycoprotein in the serum of arthritic rats: modulation by capsaicin and curcumin. Mol Cell Biochem 169, 125-134.

26. Jackson JK, Higo T, Hunter WL, et al. (2006) The antioxidants curcumin and quercetin inhibit inflammatory processes associated with arthritis. Inflamm Res $\mathbf{5 5}$, $168-175$.

27. Hanai H \& Sugimoto K (2009) Curcumin has bright prospects for the treatment of inflammatory bowel disease. Curr Pharm Des 15, 2087-2094.

28. Kurd SK, Smith N, VanVoorhees A, et al. (2008) Oral curcumin in the treatment of moderate to severe psoriasis vulgaris: a prospective clinical trial. J Am Acad Dermatol 58, 625-631. 
29. Thangapazham RL, Sharma A \& Maheshwari RK (2007) Beneficial role of curcumin in skin diseases. Adv Exp Med Biol 595, 343-357.

30. Tsui KH, Feng TH, Lin CM, et al. (2008) Curcumin blocks the activation of androgen and interlukin- 6 on prostate-specific antigen expression in human prostatic carcinoma cells I Androl 29, 661-668.

31. Liu D \& Chen Z (2013) The effect of curcumin on breast cancer cells. J Breast Cancer 16, 133-137.

32. Friedman L, Lin L, Ball S, et al. (2009) Curcumin analogues exhibit enhanced growth suppressive activity in human pancreatic cancer cells. Anticancer Drugs 20, 444-449.

33. Lim TG, Lee SY, Huang Z, et al. (2014) Curcumin suppresses proliferation of colon cancer cells by targeting CDK2. Cancer Prev Res (Phila) 7, 466-474.

34. Jackson-Bernitsas DG, Ichikawa H, Takada Y, et al. (2007) Evidence that TNF-TNFR1-TRADD-TRAF2-RIP-TAK1-IKK pathway mediates constitutive NF-kappaB activation and proliferation in human head and neck squamous cell carcinoma. Oncogene 26, 1385-1397.

35. Zhao BL, Li XJ, He RG, et al. (1989) Scavenging effect of extracts of green tea and natural antioxidants on active oxygen radicals. Cell Biophys 14, 175-185.

36. Martins RN, Harper CG, Stokes GB, et al. (1986) Increased cerebral glucose-6-phosphate dehydrogenase activity in Alzheimer's disease may reflect oxidative stress. J Neurochem 46, 1042-1045.

37. Hardy J \& Selkoe DJ (2002) The amyloid hypothesis of Alzheimer's disease: progress and problems on the road to therapeutics. Science 297, 353-356.

38. Huang HC \& Jiang ZF (2009) Accumulated amyloid- $\beta$ peptide and hyperphosphorylated tau protein: relationship and links in Alzheimer's disease. J Alzheimers Dis 16, 15-27.

39. Huang HC, Chang P, Dai XL, et al. (2012) Protective effects of curcumin on amyloid-beta-induced neuronal oxidative damage. Neurochem Res 37, 1584-1597.

40. Garcia-Alloza M, Borrelli LA, Rozkalne A, et al. (2007) Curcumin labels amyloid pathology in vivo, disrupts existing plaques, and partially restores distorted neurites in an Alzheimer mouse model. J Neurochem 102, 1095-1104.

41. Mutsuga M, Chambers JK, Uchida K, et al. (2012) Binding of curcumin to senile plaques and cerebral amyloid angiopathy in the aged brain of various animals and to neurofibrillary tangles in Alzheimer's brain. J Vet Med Sci 74, 51-57.

42. Kosik KS, Joachim CL \& Selkoe DJ (1986) Microtubuleassociated protein tau (tau) is a major antigenic component of paired helical filaments in Alzheimer disease. Proc Natl Acad Sci U S A 83, 4044-4048.

43. Glenner GG \& Wong CW (1984) Alzheimer's disease: initial report of the purification and characterization of a novel cerevrovascular amyloid protein. Biochem Biophys Res Commun 120, 885-890.

44. Masters CL, Multhaup G, Simms G, et al. (1985b) Neuronal origin of a cerebral amyloid: neurofibrillary tangles of Alzheimer's disease contain the same protein as the amyloid of plaque cores and blood vessels. EMBO J 4, 2757-2763.

45. Villemagne VL \& Rowe CC (2013) Long night's journey into the day: amyloid-beta imaging in Alzheimer's disease. J Alzheimers Dis 33, Suppl. 1, S349-S359.

46. Haass C \& Selkoe DJ (2007) Soluble protein oligomers in neurodegeneration: lessons from the Alzheimer's amyloid beta-peptide. Nat Rev Mol Cell Biol 8, 101-112.

47. Manczak M, Mao P, Calkins MJ, et al. (2010) Mitochondriatargeted antioxidants protect against amyloid-beta toxicity in Alzheimer's disease neurons. J Alzheimers Dis 20, Suppl. 2, S609-S631.
48. Cash DM, Liang Y, Ryan NS, et al. (2013) The pattern of atrophy in familial alzheimer disease: volumetric MRI results from the DIAN study. Neurology 81, 1425-1433.

49. Chetelat G, Villemagne VL, Villain N, et al. (2012) Accelerated cortical atrophy in cognitively normal elderly with high beta-amyloid deposition. Neurology 78, 477-484.

50. Chetelat G, Villemagne VL, Pike KE, et al. (2011) Independent contribution of temporal beta-amyloid deposition to memory decline in the pre-dementia phase of Alzheimer's disease. Brain 134, 798-807.

51. Reddy PH, Tripathi R, Troung Q, et al. (2012) Abnormal mitochondrial dynamics and synaptic degeneration as early events in Alzheimer's disease: implications to mitochondria-targeted antioxidant therapeutics. Biochim Biophys Acta 1822, 639-649.

52. Ferreira ST \& Klein WL (2011) The A $\beta$ oligomer hypothesis for synapse failure and memory loss in Alzheimer's disease. Neurobiol Learn Mem 96, 529-543.

53. Zhao J, Luo Y, Jang H, et al. (2012) Probing ion channel activity of human islet amyloid polypeptide (amylin). Biochim Biophys Acta 1818, 3121-3130.

54. Johnson E, Brookmeyer R \& Ziegler-Graham K (2007) Modeling the effect of Alzheimer's disease on mortality. Int J Biostat 3, Article 13, 12-21.

55. Brookmeyer R, Gray S \& Kawas C (1998) Projections of Alzheimer's disease in the United States and the public health impact of delaying disease onset. Am J Public Health 88, $1337-1342$.

56. Vickland V, Morris T, Draper B, et al. (2012) Modelling the Impact of Interventions to Delay the Onset of Dementia in Australia. Report for Alzheimers Australia. Sydney, Australia: Alzheimer's Australia Inc.

57. Bieschke J, Herbst M, Wiglenda T, et al. (2012) Small-molecule conversion of toxic oligomers to nontoxic $\beta$-sheet-rich amyloid fibrils. Nat Chem Biol 8, 93-101.

58. Ono K, Hasegawa K, Naiki H, et al. (2004) Curcumin has potent anti-amyloidogenic effects for Alzheimer's beta-amyloid fibrils in vitro. J Neurosci Res 75, 742-750.

59. Reinke AA \& Gestwicki JE (2007) Structure-activity of amyloid betta-aggregation inhibitors based on curcumin: influence of linker length and flexibility. Chem Biol Drug Des 70, 206-215.

60. Yang F, Lim GP, Begum AN, et al. (2005) Curcumin inhibits formation of amyloid beta oligomers and fibrils, binds plaques, and reduces amyloid in vivo. J Biol Chem 280, 5892-5901.

61. Ghalebani L, Wahlstrom A, Danielsson J, et al. (2012) $\mathrm{pH}$-dependence of the specific binding of $\mathrm{Cu}(\mathrm{II})$ and $\mathrm{Zn}$ (II) ions to the amyloid- $\beta$ peptide. Biochem Biophys Res Commun 421, 554-560.

62. Faller P \& Hureau C (2012) A bioinorganic view of Alzheimers disease: when misplaced metal ions (Re)direct the electrons to the wrong target. Chemistry 18, 15910-15920.

63. Banerjee R (2014) Effect of curcumin on the metal ion induced fibrillization of amyloid- $\beta$ peptide. Spectrochim Acta A Mol Biomol Spectrosc 117, 798-800.

64. Kochi A, Lee HJ, Vithanarachchi SM, et al. (2015) Inhibitory activity of curcumin derivatives towards metal-free and metal-induced amyloid-beta aggregation. Curr Alzheimer Res 12, 415-423.

65. Fu Z, Aucoin D, Ahmed M, et al. (2014) Capping of a $\beta 42$ oligomers by small molecule inhibitors. Biochemistry $\mathbf{5 3}$, 7893-7903

66. Mithu VS, Sarkar B, Bhowmik D, et al. (2014) Curcumin alters the salt bridge-containing turn region in amyloid $\beta(1-42)$ aggregates. J Biol Chem 289, 11122-11131. 
67. Caesar I, Jonson M, Nilsson K, et al. (2012) Curcumin promotes $\mathrm{A} \beta$ fibrillation and reduces neurotoxicity in transgenic drosophila (reduced neurotoxicity by promoted fibrillation). PLOS ONE 7, e31424.

68. Liu H, Li Z, Qiu D, et al. (2010) The inhibitory effects of different curcuminoids on $\beta$-amyloid protein, $\beta$-amyloid precursor protein and $\beta$-site amyloid precursor protein cleaving enzyme 1 in swAPP HEK293 cells. Neurosci Lett 485, 83-88.

69. Shimmyo Y, Kihara T, Akaike A, et al. (2008) Epigallocatechin3-gallate and curcumin suppress amyloid beta-induced beta-site APP cleaving enzyme-1 upregulation. Neuroreport 19, 1329-1333.

70. Li Y, Zhang X \& Si L (2009) Curcumin reduces A beta generation by PPAR gamma activation and BACE1 inhibition in vitro. J Neurochem 110, 61.

71. Wang X, Kim JR, Lee SB, et al. (2014) Effects of curcuminoids identified in rhizomes of Curcuma longa on BACE-1 inhibitory and behavioral activity and lifespan of Alzheimer's disease Drosophila models. BMC Complement Altern Med 14, 88-88.

72. Sathya M, Premkumar P, Karthick C, et al. (2012) BACE1 in Alzheimer's disease. Clin Chim Acta 414, 171-178.

73. Jiaranaikulwanitch J, Govitrapong P, Fokin VV, et al. (2012) From BACE1 inhibitor to multifunctionality of tryptoline and tryptamine triazole derivatives for Alzheimer's disease. Molecules 17, 8312-8333.

74. Lin R, Chen X, Li W, et al. (2008) Exposure to metal ions regulates mRNA levels of APP and BACE1 in PC12 cells: blockage by curcumin. Neurosci Lett 440, 344-347.

75. Park SY, Kim HS, Cho EK, et al. (2008) Curcumin protected PC12 cells against beta-amyloid-induced toxicity through the inhibition of oxidative damage and tau hyperphosphorylation. Food Chem Toxicol 46, 2881-2887.

76. Kim DS, Park SY \& Kim JK (2001) Curcuminoids from Curcuma longa L (Zingiberaceae) that protect PC12 rat pheochromocytoma and normal human umbilical vein endothelial cells from beta A(1-42) insult. Neurosci Lett 303, $57-61$.

77. Shi X, Zheng Z, Li J, et al. (2015) Curcumin inhibits Abeta-induced microglial inflammatory responses in vitro: involvement of ERK1/2 and p38 signaling pathways. Neurosci Lett 594, 105-110.

78. Zhang X, Yin WK, Shi XD, et al. (2011) Curcumin activates Wnt/ $\beta$-catenin signaling pathway through inhibiting the activity of GSK-3B in APPswe transfected SY5Y cells. Eur J Pharm Sci 42, 540-546.

79. Olivia CA, Vargas JY \& Inestrosa NC (2013) Wnt signaling: role in LTP, neural networks and memory. Ageing Res Rev 12, 786-800.

80. Purro SA, Dickins EM \& Salinas PC (2012) The secreted Wnt antagonist Dickkopf-1 is required for amyloid B-medicated synaptic loss. J Neurosci 32, 3492-3498.

81. Wan W, Xia S, Kalionis B, et al. (2014) The role of Wnt signaling in the development of Alzheimer's disease: a potential therapeutic target. Biomed Res Int 2014, 1-9.

82. Parr C, Mirzaei N \& Christian M (2015) Activation of the Wnt/beta-catenin pathway represses the transcription of the beta-amyloid precursor protein cleaving enzyme (BACE-1) via binding of T-cell factor- 4 to BACE1 promoter. FASEB J 29, 623-635.

83. Khan MA, Akhtar N, Sharma V, et al. (2015) Product development studies on sonocrystallized curcumin for the treatment of gastric cancer. Pharmaceutics 7, 43-63.

84. Bates KA, Verdile G, Li QX, et al. (2009) Clearance mechanisms of Alzheimer's amyloid-beta peptide: implications for therapeutic design and diagnostic tests. Mol Psychiatry 14, 469-486.

85. Foster JK, Verdile G, Bates KA, et al. (2009) Immunization in Alzheimer's disease: naive hope or realistic clinical potential? Mol Psychiatry 14, 239-251.

86. Fiala M, Lin J, Ringman J, et al. (2005) Ineffective phagocytosis of amyloid-beta by macrophages of Alzheimer's disease patients. $J$ Alzheimers Dis 7, 221-232.

87. Zhang L, Fiala M, Cashman J, et al. (2006) Curcuminoids enhance amyloid-beta uptake by macrophages of Alzheimer's disease patients. J Alzheimers Dis 10, 1-7.

88. Fiala M, Liu PT, Espinosa-Jeffrey A, et al. (2007) Innate immunity and transcription of MGAT-II and toll-like receptors in Alzheimer's disease patients are improved by bisdemethoxycurcumin. Proc Natl Acad Sci U S A 104, 12849-12854.

89. Masoumi A, Goldenson B, Ghirmai S, et al. (2009) 1 alpha,25-Dihydroxyvitamin $\mathrm{D}_{3}$ interacts with curcuminoids to stimulate amyloid-beta clearance by macrophages of Alzheimer's disease patients. J Alzheimers Dis 17, 703-717.

90. Mizwicki MT, Menegaz D, Barrientos-Durán A, et al. (2012) Genomic and nongenomic signaling induced by $1 \alpha, 25(\mathrm{OH})$ 2 -vitamin $\mathrm{D}_{3}$ promotes the recovery of amyloid- $\beta$ phagocytosis by Alzheimer's disease macrophages. J Alzheimers Dis 29, 51-62.

91. Soni KB \& Kuttan R (1992) Effect of oral curcumin administration on serum peroxides and cholesterol levels in human volunteers. Indian J Physiol Pharmacol 36, 273-275.

92. Soudamini KK, Unnikrishnan MC, Soni KB, et al. (1992) Inhibition of lipid peroxidation and cholesterol levels in mice by curcumin. Indian J Physiol Pharmacol 36, 239-243.

93. Sreejayan N \& Rao MNA (1994) Curcuminoids as potent inhibitors of lipid peroxidation. J Pharm Pharmacol 46, 1013-1016.

94. Peschel D, Koerting R \& Nass N (2007) Curcumin induces changes in expression of genes involved in cholesterol homeostasis. J Nutr Biochem 18, 113-119.

95. Feng D, Ohlsson L \& Duan RD (2010) Curcumin inhibits cholesterol uptake in Caco-2 cells by down-regulation of NPC1L1 expression. Lipids Health Dis 9, 40-45.

96. Kim M \& Kim Y (2010) Hypocholesterolemic effects of curcumin via up-regulation of cholesterol 7a-hydroxylase in rats fed a high fat diet. Nutr Res Pract 4, 191-195.

97. Tu Y, Sun D, Zeng X, et al. (2014) Piperine potentiates the hypocholesterolemic effect of curcumin in rats fed on a high fat diet. Exp Ther Med 8, 260-266.

98. Zambón D, Quintana M, Mata P, et al. (2010) Higher incidence of mild cognitive impairment in familial hypercholesterolemia. Am J Med 123, 267-274.

99. Refolo LM, Pappola MA, Malester B, et al. (2000) Hypercholesterolemia accelerates the Alzheimer's amyloid pathology in a transgenic mouse model. Neurobiol Dis 7, 690-691.

100. Xiao Z, Zhang A, Lin J, et al. (2014) Telomerase: a target for therapeutic effects of curcumin and a curcumin derivative in Abeta insult in vitro. PLOS ONE 9, e101251.

101. Lim GP, Chu T, Yang F, et al. (2001) The curry spice curcumin reduces oxidative damage and amyloid pathology in an Alzheimer transgenic mouse. J Neurosci 21, 8370-8377.

102. Wang YJ, Thomas P, Zhong JH, et al. (2009) Consumption of grape seed extract prevents amyloid- $\beta$ deposition and attenuates inflammation in brain of an Alzheimer's disease mouse. Neurotox Res 15, 3-14.

103. Ma QL, Yang F, Rosario ER, et al. (2009) Beta-amyloid oligomers induce phosphorylation of tau and inactivation of insulin receptor substrate via c-Jun N-terminal kinase signaling: suppression by omega-3 fatty acids and curcumin. J Neurosci 29, 9078-9089. 
104. Frautschy SA, Hu W, Kim P, et al. (2001) Phenolic anti-inflammatory antioxidant reversal of Abeta-induced cognitive deficits and neuropathology. Neurobiol Aging 22, 993-1005.

105. Fenech M \& Thomas P (2010) Grape seed polyphenols and curcumin reduce genomic instability events in a transgenic mouse model for Alzheimer's disease. Alzheimers Dement $\mathbf{6}$ S70-S72.

106. Belviranli M, Okudan N, Atalik K, et al. (2013) Curcumin improves spatial memeory and decreases oxidative damage in aged female rats. Biogerontology 14, 187-196.

107. Ahmed T, Enam SA \& Gilani AH (2010) Curcuminoids enhance memory in an amyloid-infused rat model of Alzheimer's disease. Neuroscience 169, 1296-1306.

108. Kim SJ, Son TG, Park HR, et al. (2008) Curcumin stimulates proliferation of embryonic neural progenitor cells and neurogenesis in the adult hippocampus. J Biol Chem 283, $14497-14505$.

109. Gerenu G, Liu K, Chojnacki JE, et al. (2015) Curcumin/melatonin hybrid 5-(4-hydroxy-phenyl)-3-oxo-pentanoic acid [2-(5-methoxy-1H-indol-3-yl)-ethyl]-amide ameliorates ADlike pathology in the APP/PS1 mouse model. ACS Chem Neurosci 6, 1393-1399.

110. Yanagisawa D, Ibrahim NF, Taguchi H, et al. (2015) Curcumin derivative with the substitution at $\mathrm{C}-4$ position, but not curcumin, is effective against amyloid pathology in APP/ PS1 mice. Neurobiol Aging 36, 201-210.

111. Dong S, Zeng Q, Mitchell ES, et al. (2012) Curcumin enhances neurogenesis and cognition in aged rats: implications for transcriptional interactions related to growth and synaptic plasticity. PLOS ONE 7, e31211.

112. Ghoneim AI, Abdel-Naim AB, Khalifa AE, et al. (2002) Protective effects of curcumin against ischaemia/reperfusion insult in rat forebrain. Pharmacol Res 46, 273-279.

113. Thiyagarajan M \& Sharma SS (2004) Neuroprotective effect of curcumin in middle cerebral artery occlusion induced focal cerebral ischemia in rats. Life Sci 74, 969-985.

114. Jiang J, Wang W, Sun YJ, et al. (2007) Neuroprotective effect of curcumin on focal cerebral ischemic rats by preventing blood-brain barrier damage. Eur J Pharmacol 561, 54-62.

115. Wang YF, Gu YT, Qin GH, et al. (2013) Curcumin ameliorates the permeability of the blood-brain barrier during hypoxia by upregulating heme oxygenase- 1 expression in brain microvascular endothelial cells. $J$ Mol Neurosci 51, 344-351.

116. Tsai YM, Chien CF, Lin LC, et al. (2011) Curcumin and its nano-formulation: the kinetics of tissue distribution and blood-brain barrier penetration. Int J Pharm 416, 331-338.

117. Cheng KK, Yeung CF, Ho SW, et al. (2013) Highly stabilized curcumin nanoparticles tested in an in vitro blood-brain barrier model and in Alzheimer's disease Tg2576 mice. AAPS J 15, 324-336.

118. Anand P, Nair HB, Sung B, et al. (2010) Design of curcumin loaded PLGA nanoparticles formulation with enhanced cellular uptake, and increased bioactivity in vitro and superior bioavailability in vivo. Biochem Pharmacol 79, 330-338.

119. Zona C \& La Ferla B (2011) Synthesis of labeled curcumin derivatives as tools for in vitro blood brain barrier trafficking studies. J Label Compd Radiopharm 54, 629-632.

120. Re F, Gregori M \& Masserini M (2012) Nanotechnology for neurodegenerative disorders. Nanomed Nanotechnol 8, S51-S58.

121. Shahani K, Swaminathan SK, Freeman D, et al. (2010) Injectable sustained release microparticles of curcumin: a new concept for cancer chemoprevention. Cancer Res $\mathbf{7 0}$ $4443-4452$.
122. Chiu SS, Lui E, Majeed M, et al. (2011) Differential distribution of intravenous curcumin formulations in the rat brain. Anticancer Res 31, 907-911.

123. Shaikh J, Ankola DD, Beniwal V, et al. (2009) Nanoparticle encapsulation improves oral bioavailability of curcumin by at least 9-fold when compared to curcumin administered with piperine as absorption enhancer. Eur J Pharm Sci 37, 223-230.

124. Ahmed T \& Gilani AH (2009) Inhibitory effect of curcuminoids on acetylcholinesterase activity and attenuation of scopolamine-induced amnesia may explain medicinal use of turmeric in Alzheimer's disease. Pharmocol Biochem Behav 91, 554-559.

125. Gauthier S \& Molinuevo JL (2013) Benefits of combined cholinesterase inhibitor and memantine treatment in moderate-severe AD. Alzheimers Dement 9, 326-331.

126. Peeyush KT, Antony S, Sonan S, et al. (2011) Role of curcumin in the prevention of cholinergic mediated cortical dysfunctions in streptozotocin-induced diabetic rats. Mol Cell Endocrinol 331, 1-10.

127. Rajasekar N, Dwivedi S, Tota SK, et al. (2013) Neuroprotective effect of curcumin on okadaic acid induced memory impairment in mice. Eur J Pharmacol 715, 381-394.

128. Tiwari V \& Chopra K (2013) Protective effect of curcumin against chronic alcohol-induced cognitive deficits and neuroinflammation in the adult rat brain. Neuroscience 6, 147-158.

129. Orhan IE (2013) Nature: a substantial source of auspicious substances with acetylcholinesterase inhibitory action. Curr Neuropharmacol 11, 379-387.

130. Bulteau AL, Moreau M, Saunois A, et al. (2006) Algae extractmediated stimulation and protection of proteasome activity within human keratinocytes exposed to UVA and UVB irradiation. Antioxid Redox Signal 8, 136-143.

131. Cole GM, Teter B \& Frautschy SA (2007) Neuroprotective effects of curcumin. Adv Exp Med Biol 595, 197-212.

132. Ikonomovic MD, Abrahamson EE, Uz T, et al. (2008) Increased 5-lopoxygenase immunoreactivity in the hippocampus of patients with Alzheimer's disease. J Histochem Cytochem 56, 1065-1073.

133. Qu J, Uz T \& Manev H (2000) Inflammatory 5-LOX mRNA and protein are increased in brain of aging rats. Neurobiol Aging 21, 647-652.

134. Firuzi O, Zhuo J, Chinnici CM, et al. (2008) 5-Lipoxygenase gene disruption reduces amyloid- $\beta$ pathology in a mouse model of Alzheimer's disease. FASEB J 22, 1169-1178.

135. Ohno M (2014) Roles of eIF2 $\alpha$ kinases in the pathogenesis of Alzheimer's disease. Front Mol Neurosci 7, 1-8.

136. Valera E, Dargusch R, Maher PA, et al. (2013) Modulation of 5-lipoxygenase in proteotoxicity and Alzheimer's disease. J Neurosci 33, 10512-11052.

137. Baum L, Lam C, Cheung S, et al. (2008) Six-month randomized, placebo-controlled, double-blind, pilot clinical trial of curcumin in patients with Alzheimer disease. J Clin Psychopharm 28, 110-114.

138. Ringman JM, Frautschy SA, Cole GM, et al. (2005) A potential role of the curry spice curcumin in Alzheimer's disease. Curr Alzheimer Res 2, 131-136.

139. Commandeur J \& Vermeulen N (1996) Cytotoxicity and cytoprotective activities of natural compounds. The case of curcumin. Xenobiotica 26, 667-680.

140. Ganguli M, Chandra V, Kamboh MI, et al. (2000) Apolipoprotein E polymorphism and Alzheimer disease: the Indo-US cross-national dementia study. Arch Neurol 57, 824-830.

141. Chandra V, Pandav R, Dodge H, et al. (2001) Incidence of Alzheimer's disease in a rural community in India The IndoUS study. Neurology 57, 985-989. 
142. Shaji S, Bose S \& Verghese A (2005) Prevalence of dementia in an urban population in Kerala, India. B J Psychiatry 186, 136-140.

143. Ng TP, Chiam PC, Lee T, et al. (2006) Curry consumption and cognitive function in the elderly. Am J Epidemiol 164, 898-906.

144. Cox KH, Pipingas A \& Scholey AB (2015) Investigation of the effects of solid lipid curcumin on cognition and mood in a healthy older population. J Psychopharmacol 29, 642-651.

145. Ringman JM, Frautschy SA, Teng E, et al. (2012) Oral curcumin for Alzheimer's disease: tolerability and efficacy in a 24-week randomized, double blind, placebocontrolled study. Alzheimer's Res Ther 4, 43-51.

146. DiSilvestro RA, Joseph E, Zhao S, et al. (2012) Diverse effects of a low dose supplement of lipidated curcumin in healthy middle aged people. Nutr J 11, 79-87.

147. van Stegerena A, Rohlederb N, Everaerda W, et al. (2006) Salivary alpha amylase as marker for adrenergic activity during stress: effect of betablockade. Psychoneuroendocrinology 31, 137-141.

148. Gallacher DV \& Petersen OH (1983) Stimulus-secretion coupling in mamalian salivary glands. Intern Rev Physiol 28, $1-52$.

149. Chatterton RT, Vogelsong KM, Lu YC, et al. (1996) Salivary alpha-amylase as a measure of endogenous adrenergic activity. Clin Physiol 16, 433-448.

150. Hishikawa N, Takahashi Y, Amakusa Y, et al. (2012) Effects of turmeric on Alzheimer's disease with behavioral and psychological symptoms of dementia. Ayu 33, 499-504.

151. Mastroeni D, Grover A, Delvaux E, et al. (2011) Epigenetic mechanisms in Alzheimer's disease. J Neurobiol Aging 32, 1161-1180.

152. Daniilidou M, Koutroumani M \& Tsolaki M (2011) Epigenetic mechanisms in Alzheimer's disease. Curr Med Chem 18, 1751-1756.

153. Balazs R, Vernon J \& Hardy J (2011) Epigenetic mechanisms in Alzheimer's disease:progress but much to do. Neurobiol Aging 32, 1181-1187.

154. Chouliaras L, Rutten BPF, Kenis G, et al. (2010) Epigenetic regulation in the pathophysiology of Alzheimer's disease. Prog Neurobiol 90, 498-510.

155. Teiten MH, Dicato M \& Diederich M (2013) Curcumin as a regulator of epigenetic events. Mol Nutr Food Res 57, $1619-1629$.

156. Reuter S, Gupta SC, Park B, et al. (2011) Epigenetic changes induced by curcumin and other natural compounds. Genes Nutr 6, 93-108.

157. Du L, Xie Z, Wu LC, et al. (2012) Reactivation of RASSF1A in breast cancer cells by curcumin. Nutr Cancer 64, 1228-1235.

158. Sezgin Z \& Dincer Y (2014) Alzheimer's disease and epigenetic diet. Neurochem Int 78, 105-116.

159. Li YJ, Xu M, Gao ZH, et al. (2013) Alterations of serum levels of BDNF-related miRNAs in patients with depression. PLOS ONE 8, e63648.

160. Lopresti AL, Maes M, Marker GL, et al. (2014) Curcumin for the treatment of major depression: a randomised, double-blind, placebo controlled study. J Affect Disord 167, 368-375.

161. Davinelli S, Calabrese V, Zella D, et al. (2014) Epigenetic nutraceutical diets in Alzheimer's disease. J Nutr Health Aging 18, 800-805.

162. Ansari R, Mahta A, Mallack E, et al. (2014) Hyperhomocysteinemia and neurologic disorders: a review. J Clin Neurol 10, 281-288.

163. Mattson MP \& Shea TB (2003) Folate and homocysteine metabolism in neural plasticity and neurodegenerative disorders. Trends Neurosci 26, 137-146.
164. Fux R, Kloor D, Hermes M, et al. (2005) Effect of acute hyperhomocysteinemia on methylation potential of erthrocytes and on DNA methylation of lymphocytes in healthy male volunteers. Am J Renal Physiol 289, F786-F792.

165. Ataie A, Sabetkasaei M, Haghparast A, et al. (2010) Curcumin exerts neuroprotective effects against homocysteine intracerebroventricular injection-induced cognitive impariement and oxidative stress in rat brain. J Med Food 13, 821-826.

166. Cheng $\mathrm{AL}, \mathrm{Hsu} \mathrm{CH}$, Lin $\mathrm{CH}$, et al. (2001) Phase I clinical trial of curcumin, a chemopreventative agent, in patients with high-risk or pre-malignant lesions. Anticancer Res 21 , 2895-2900.

167. Gupta SC, Kismali G \& Aggarwal BB (2013) Curcumin, a component of turmeric: from farm to pharmacy. Biofactors 39, 2-13.

168. Pan CJ, Tang JJ, Weng YJ, et al. (2006) Preparation, characterization and anticoagulation of curcumin-eluting controlled biodgradable coating stents. J Control Release 116, 2-49.

169. Dong-Chan K, Sae-Kwang K \& Jong-Sup B (2012) Anticoagulant activities of curcumin and its derivative. BMB Rep 45, 221-226.

170. Belkacemi A, Doggui S, Dao L, et al. (2011) Challenges associated with curcumin therapy in Alzheimer disease. Exp Rev Mol Med 13, e34.

171. Sharma RA, Steward WP \& Gescher AJ (2007) The molecular targets and therapeutic uses of curcumin in health and disease. Adv Exp Med Biol 595, 453-470.

172. Ireson C, Orr S \& Jones DJL (2001) Characterization of metabolites of the chemopreventative agent curcumin in human and rat hepatocytes and in the rat in vivo, and evaluation of their ability to inhibit phorbol ester-induced prosaglandin E2 production. Cancer Res 61, 1058-1064.

173. Benny M \& Anthony B (2006) Bioavailability of Biocurcumax ${ }^{\mathrm{TM}}\left(\mathrm{BCM}-95^{\mathrm{TM}}\right)$. Research and Development Laboratory, Arjuna Natural Extracts Ltd, Binanipuram.

174. Pescosolido N, Giannotti R, Plateroti AM, et al. (2014) Curcumin: therapeutical potential in ophthalmology. Planta Med 80, 249-254.

175. Rachmawati H, Budiputra DK \& Mauludin R (2014) Curcumin nanoemulsion for transdermal application: formulation and evaluation. Drug Dev Ind Pharm 41, 560-566.

176. McClure R, Yanagisawa D, Stec D, et al. (2015) Inhalable curcumin: offering the potential for translation to imaging and treatment of Alzheimer's disease. J Alzheimers Dis 44, 283-295.

177. Antony B, Merina B, Iyer VS, et al. (2008) A pilot cross-over study to evaluate human oral bioavailability of BCM-95CG (Biocurcumax), a novel bioenhanced preparation of curcumin. Indian J Pharm Sci 70, 445-449.

178. Merina B \& Antony B (2006) Bioavailability of Biocurcumax (BCM-095). Spice India 2, 11-16.

179. Jayaraj RL, Elangovan N, Dhanalakshmi C, et al. (2014) CNB-001, a novel pyrazole derivative mitigates motor impairments associated with neurodegeneration via suppression of neuroinflammatory and apoptotic response in experimental Parkinson's disease mice. Chem Biol Interact 220, 149-157.

180. Maher P, Akaishi T, Schubert D, et al. (2010) A pyrazole derivative of curcumin enhances memory. Neurobiol Aging 31, 706-709.

181. Liu Y, Dargusch R, Maher P, et al. (2008) A broadly neuroprotective derivative of curcumin. J Neurochem 105, 1336-1345.

182. Prasad S, Tyagi AK \& Aggarwal BB (2014) Recent developments in delivery, bioavailability, absorption and metabolism of curcumin: the golden pigment from golden spice. Cancer Res Treat 46, 2-18.

183. Stockert JC, Del Castillo P, Gomez A, et al. (1989) Fluorescence reaction of chromatin by curcumin. Z Naturforsch C 44, 327-329. 
184. Wang F, Wu X, Wang F, et al. (2006) The sensitive fluorimetric method for the determination of curcumin using the enhancement of mixed micelle. J Fluoresc 16, 53-59.

185. Ryu EK, Choe YS, Lee KH, et al. (2006) Curcumin and dehydrozingerone derivatives: synthesis, radiolabeling, and evaluation for $\beta$-amyloid plaque imaging. J Med Chem 49, 6111-6119.

186. Mohorko N, Repovš G, Popovic M, et al. (2010) Curcumin labeling of neuronal fibrillar tau inclusions in human brain samples. J Neuropathol Exp Neurol 69, 405-414.

187. Koronyo-Hamaoui M, Koronyo Y, Ljubimov AV, et al. (2011) Identification of amyloid plaques in retinas from Alzheimer's patients and noninvasive in vivo optical imaging of retinal plaques in a mouse model. Neuroimage, S204-S217.
188. Kayabasi U, Sergott RC \& Rispoli M (2014) Retinal examination for the diagnosis of Alzheimer's disease. Int J Ophthalmol Clin Res 1, 1-4.

189. Cheng KK, Chan PS, Fan S, et al. (2015) Curcumin-conjugated magnetic nanoparticles for detecting amyloid plaques in Alzheimer's disease mice using magnetic resonance imaging (MRI). Biomaterials 44, 155-172.

190. Patil R, Gangalum PR, Wagner S, et al. (2015) Curcumin targeted, polymalic acid-based MRI contrast agent for the detection of abeta plaques in Alzheimer's disease. Macromol Biosci 15, 1212-1217.

191. Frost S, Martins RN \& Kanagasingam Y (2010) Ocular biomarkers for early detection of Alzheimer's disease. J Alzheimers Dis 22, 1-16. 